\title{
Integration of biology, ecology and engineering for sustainable algal-based biofuel and bioproduct biorefinery
}

\author{
James Allen², Serpil Unlu ${ }^{1 *}$ (D), Yaşar Demirel ${ }^{1}$, Paul Black ${ }^{2}$ and Wayne Riekhof ${ }^{3}$
}

\begin{abstract}
Despite years of concerted research efforts, an industrial-scale technology has yet to emerge for production and conversion of algal biomass into biofuels and bioproducts. The objective of this review is to explore the ways of possible integration of biology, ecology and engineering for sustainable large algal cultivation and biofuel production systems. Beside the costs of nutrients, such as nitrogen and phosphorous, and fresh water, upstream technologies which are not ready for commercialization both impede economic feasibility and conflict with the ecological benefits in the sector. Focusing mainly on the engineering side of chemical conversion of algae to biodiesel has also become obstacle. However, to reduce the costs, one potential strategy has been progressing steadily to synergistically link algal aquaculture to the governmentally mandated reduction of nitrogen and phosphorous concentrations in municipal wastewater. Recent research also supports the suppositions of scalability and cost reduction. Noticeably, less is known of the economic impact of conversion of the whole algae-based biorefinery sector with additional biochemical and thermochemical processes and integration with ecological constraints. This review finds that a biorefinery approach with integrated biology, ecology, and engineering could lead to a feasible algal-based technology for variety of biofuels and bioproducts.
\end{abstract}

Keywords: Biofuel, Bioproduct, Cultivation, Harvesting, Conversion processes, Ecology, Municipal wastewater, EROI, Sustainability

\section{Introduction}

The United States Energy Independence and Security Act of 2007 set targets for alternative biofuel production in the United States to be achieved by 2022; five billion gallons/ year are marked to be made by advanced biofuels-based diesel and other biofuels (Davis et al. 2016; Fortier and Sturm 2012; Kheshgi and Jain 2003; Nrel 1998; Rodolfi et al. 2009; US Congress 2007). Algae-based biofuels can contribute to meet these goals of improving energy security and reducing GHG emissions from the transportation sector (Muylaert et al. 2015). It is widely recognized that algal biomass has the potential to supersede terrestrial bioenergy crops as a platform for biofuels and

\footnotetext{
*Correspondence: Serpil.unlu@huskers.unl.edu

1 Department of Chemical and Biomolecular Engineering, University of Nebraska Lincoln, 207 Othmer Hall, Lincoln 68588-0643, Nebraska, USA Full list of author information is available at the end of the article
}

bioproducts production. Algae can be grown using nonarable areas such as lakes, oceans or deserts, thus avoiding the current problem of land use competition with food supply chain. Some microalgae can grow under saline conditions, which support their use in desert zones near the ocean when freshwater supply is not feasible (Mussgnug et al. 2010a, b; Stephens et al. 2010). Microalgae can fix $\mathrm{CO}_{2}$ 10-50 times more efficient than other energy plants (Brennan and Owende 2010; Demirel 2018a; Wang and Chen 2009). High photosynthetic carbon sequestration efficiencies and carbon capture percentages of $90 \%$ paired with the ability to harvest and use the totality of the biomass make algae very well suited as a source for biofuels and bioproducts (Demirel 2018b). In general, the use of photosynthetic organisms as a feedstock mitigates ever-increasing anthropogenic $\mathrm{CO}_{2}$ emissions.

The 2012 National Research Council's report on sustainable development of algal biofuels concluded the 
need for (i) research, development, and demonstration of algal strain selection, (ii) Energy Return on Investment (EROI) that is comparable to other transportation fuels, and (iii) the use of wastewater and recycling nutrients for cultivating algae for biofuels (National Research Council 2012a). The report concluded that the algal biofuel production sufficient to meet at least $5 \%$ of US demand for transportation fuels would have a positive impact on energy and environment as a whole. However, despite their excellent potential and the well-studied cultivation options, microalgae are not yet commercially viable feedstock for biofuels and bioproducts, owing mainly to the cost of harvesting and extracting of lipids (Mchenry 2015). Additional innovations are needed to realize the full potential of algal biotechnology (National Research Council 2012b; Ranjith Kumar et al. 2015). A national assessment of land requirements for algae cultivation that takes into account climatic conditions, fresh water, inland and coastal saline water, wastewater resources, and $\mathrm{CO}_{2}$ sources would help to estimate the potential of algal biofuels that could be produced economically. This study reviews the impacts of integrating biology, engineering, and ecology for a sustainable algal-based biofuels and bioproducts operation, including current information on industrial microalgae strain and cultivation, conversion processes beside transesterification, and cultivation using the nutrients recovered from wastewater treatment. The feasibility of algal-based biofuels and bioproducts within ecological constraints, and the future role microalgae can play in food-energy-water nexus are also discussed.

\section{Integration of disciplines}

Improving the fundamental understanding of algae-based biofuels and bioproducts operation requires to identify potential paradigm shifts by integration of biology, ecology and engineering (Scott et al. 2010). The aspect of biology will mostly involve understanding the capabilities of strain and/or communities of strain, cultivation with optimized growth and stability, lipid metabolic pathways, maintenance, and carbon capture, as well as the protection of algae culture from contamination by bacteria, predators, and competing algae/cyanobacteria. Engineering will play its role in supplying resources, $\mathrm{CO}_{2}$, light, and energy, integration of energy, extraction and conversion of lipid into fuels and bioproducts, waste and co-product processing with possible recycling, mass and energy balances, cost analysis, and sustainability assessments. Applications of aquatic ecology can play an important role (Smith and Mcbride 2015) in optimizing nutrients supplied to algal cultivation systems, designing and constructing biotic communities that will help to maximize algal biomass yields and minimize losses from grazing and infectious disease, helping to guide the magnitude and frequency of algal crop harvests, and creating biologically adaptive algal biomass production systems that are both resistant and resilient to future climate changes (Bartley et al. 2016; Shurin et al. 2013). The ecological constraints may be the least understood that causes the obstacles to successfully integrate the biology, engineering, and ecology in a large and sustainable algal cultivation system.

\section{Biology}

The type and quantity of lipids accumulated (saturated, polyunsaturated fatty acids, glycolipids, and triacylglycerol) depends on the microalgae species and the growth conditions. Fatty acids can be saturated (contain no double bonds in the acyl chain - see Table 1), or unsaturated (with either one monounsaturated or multiple polyunsaturated double bond(s)-Table 2). Nutrient ( $\mathrm{N}$ or P) deficiency and high radiation can cause considerable increase in saturated and monosaturated fatty acids, which are mainly associated with storage of triglyceride acids (TGA) in microalgae. When light irradiance is low, mainly phospholipids and glycolipids, which are polar lipids and associated with cell membranes, are synthesized (Hu et al. 2008; Rodolfi et al. 2009).

\section{Microalgae strains}

Many strains of microalgae can grow and produce oil using organic carbon sources in dark (heterotrophy) or light (mixotrophy) conditions. Growth of microalgae needs resources including carbon $(\mathrm{C})$, nitrogen $(\mathrm{N})$, and phosphorous $(\mathrm{P})$. Lipid productivities, and in some cases oil content, are normally higher in heterotrophic conditions due to higher growth rates and final cell concentrations (Rodolfi et al. 2009). The quality of oil produced is often less unsaturated and, therefore, more suitable for biodiesel oil production than those produced under photoautotrophic conditions. Heterotrophy can be used to reduce the cost of biodiesel oil production, but the effectiveness of the various organic carbons in supporting cell growth and oil accumulation depends on the strain and

\begin{tabular}{|c|c|c|c|c|}
\hline Symbol & $\begin{array}{l}\text { Common } \\
\text { name }\end{array}$ & $\begin{array}{l}\text { Systematic } \\
\text { name }\end{array}$ & Structure & Mp. $\left({ }^{\circ} \mathrm{C}\right)$ \\
\hline $12: 0$ & Lauric acid & Dodecanoic acid & $\mathrm{CH}_{3}\left(\mathrm{CH}_{2}\right)_{10} \mathrm{COOH}$ & 44.2 \\
\hline 14:0 & Myristic acid & $\begin{array}{l}\text { Tetradecanoic } \\
\text { acid }\end{array}$ & $\mathrm{CH}_{3}\left(\mathrm{CH}_{2}\right)_{12} \mathrm{COOH}$ & 52.0 \\
\hline $16: 0$ & Palmitic acid & $\begin{array}{l}\text { Hexadecanoic } \\
\text { acid }\end{array}$ & $\mathrm{CH}_{3}\left(\mathrm{CH}_{2}\right){ }_{14} \mathrm{COOH}$ & 63.1 \\
\hline 18:0 & Stearic acid & $\begin{array}{l}\text { Octadecanoic } \\
\text { acid }\end{array}$ & $\mathrm{CH}_{3}\left(\mathrm{CH}_{2}\right)_{16} \mathrm{COOH}$ & 69.6 \\
\hline $20: 0$ & $\begin{array}{l}\text { Arachidic } \\
\text { acid }\end{array}$ & Eicosanoic acid & $\mathrm{CH}_{3}\left(\mathrm{CH}_{2}\right)_{18} \mathrm{COOH}$ & 75.4 \\
\hline
\end{tabular}

Mp. melting point temperature 
Table 2 Names and structures of the most common unsaturated fatty acids (Hu et al. 2008; Rodolfi et al. 2009)

\begin{tabular}{|c|c|c|c|c|}
\hline Symbol & Common name & Systematic name & Structure & Mp. $\left({ }^{\circ} \mathrm{C}\right)$ \\
\hline 16:1D9 & Palmitoleic acid & Hexadecenoic acid & $\mathrm{CH}_{3}\left(\mathrm{CH}_{2}\right)_{5} \mathrm{CH}=\mathrm{CH}-\left(\mathrm{CH}_{2}\right)_{7} \mathrm{COOH}$ & -0.5 \\
\hline 18:1D9 & Oleic acid & 9-Octadecenoic acid & $\mathrm{CH}_{3}\left(\mathrm{CH}_{2}\right)_{7} \mathrm{CH}=\mathrm{CH}-\left(\mathrm{CH}_{2}\right)_{7} \mathrm{COOH}$ & 13.4 \\
\hline $18: 2 \mathrm{D} 9,12$ & Linoleic acid & 9,12-Octadecadienoic acid & $\mathrm{CH}_{3}\left(\mathrm{CH}_{2}\right)_{4}\left(\mathrm{CH}=\mathrm{CHCH}_{2}\right)_{2}\left(\mathrm{CH}_{2}\right)_{6} \mathrm{COOH}$ & -9.0 \\
\hline 18:3D9,12,15 & a-Linolenic acid & $9,12,15$-Octadecatrienoic acid & $\mathrm{CH}_{3} \mathrm{CH}_{2}\left(\mathrm{CH}=\mathrm{CHCH}_{2}\right)_{3}\left(\mathrm{CH}_{2}\right)_{6} \mathrm{COOH}$ & -17.0 \\
\hline $20: 4 \mathrm{D} 5,8,11,14$ & Arachidonic acid & 5,8,11,14-Eicosatetraenoic acid & $\mathrm{CH}_{3}\left(\mathrm{CH}_{2}\right)_{4}\left(\mathrm{CH}=\mathrm{CHCH}_{2}\right)_{4}\left(\mathrm{CH}_{2}\right)_{2} \mathrm{COOH}$ & -49.0 \\
\hline $20: 5 \mathrm{D} 5,8,11,14,17$ & EPA & 5,8,11,14,17-Eicosapentaenoic-acid & $\mathrm{CH}_{3} \mathrm{CH}_{2}\left(\mathrm{CH}=\mathrm{CHCH}_{2}\right)_{5}\left(\mathrm{CH}_{2}\right)_{2} \mathrm{COOH}$ & -54.0 \\
\hline $22: 6$ D4,7,10,13,16,19 & $\mathrm{DHA}$ & Docosahexaenoic acid & $22: 6(n-3)$ & \\
\hline
\end{tabular}

Mp. melting point temperature

other culture conditions (Eroglu et al. 2015; Rodolfi et al. 2009).

Aside from culture management, temperature, and light radiation can play important role for algae-based biotechnology. High lipid yield and growth rate improve the extractable lipid and, hence, the production costs; however, there is commonly a tradeoff between lipid quantities and reproductive growth. Changing this behavior may be difficult since the specific calorific value of fuel of lipids $(38.9 \mathrm{~kJ} / \mathrm{g})$ is higher than that of carbohydrates (15.6-17.5 kJ/g). Besides genetic and metabolic engineering, strain-based solutions may help to maintain high lipid levels in the absence of $\mathrm{N}$. The strain selected must be productive in the changing culture environment (i.e., temperature, mixing, light radiation) either having a constitutively high lipid yield or being able to accumulate lipid under nutrient deficiency. Genetic and metabolic engineering could help to increase lipid yield and eliminate photosaturation, and photoinhibition to decrease the cost of biofuel production (Rodolfi et al. 2009). There are several candidate species for full-scale algae production based on algal structure, physiology and ecology, and methods for extraction of algal oils for production of biofuel and bioproducts. For example, Rodolfi et al. (2009) screened 30 microalgal strains and found that three members of the marine genus Nannochloropsis demonstrated the best combination of both biomass productivity $(\sim 0.2 \mathrm{~g} / \mathrm{L}$ day) and lipid content ( $30 \mathrm{wt} \%)$.

Table 3 shows a summary of reported lipid contents with some of their effective temperatures and salinities. Also shown are lipid contents in nutrient deficient media, notably $\mathrm{N}$ and Silicon (S), which have been shown to affect lipid content (Nrel 1998). The dominant strains of algae that are commonly found in wastewater ponds include Euglenia, Scenedesmus, Selenastrum, Chlorella, and Actinastrum. They are able to strip nutrients and organic matter from wastewater, grow rapidly, and produce a significant level of oil (Lyon et al. 2015).

Strains of Nannochloropsis, Phaeodactylum, and Chlorella show some of the highest biomass productivities and, therefore, promise as the strain of choice for industrial-scale productions (Griffiths and Harrison 2009). Nannochloropsis has available technical data for entire production line (Davis et al. 2011; Ehimen et al. 2011). Choice of strain dictates some process parameters including growth (saline water), auto-flocculation for concentrating, and high-value products. In terms of high growth rate and lipid contents, some of the best biofuel microalgae strains are Nannochloropis spp., Chlorella. vulgaris, Chlorella minutissima, Chlorella protothecoides, Botryococcus braunii, Chlorella emersonii, Spirulina platensis, Spirulina maxima, Dunaliella tertiolecta, Phaeodactylum tricornutum, Scenedesmus obliquus, Chlorococcum spp., Crypthecodinium cohnii, Chlamydomonas reinhardtii, Dunaliella salina, Schizochytrium spp., and Microcystis aeruginosa (Bahadar and Bilal Khan 2013).

Various microalgae can bio-remediate atmospheric $\mathrm{CO}_{2}$. Raeesossadati and Ahmadzadeh (2015) reported biomass concentration, biomass productivity, and $\mathrm{CO}_{2}$ fixation rates of several microalgae and cyanobacteria species under different $\mathrm{CO}_{2}$ concentrations and culture conditions; microalgal species of Scenedesmuss obliquss, Dunaliella tertiolecta, Chlorella vulgaris, Phormidium spp., Amicroscopica negeli, and Chlorococcum littorale are able to bio-remediate $\mathrm{CO}_{2}$ effectively. Furthermore, coccolithophorid microalgae such as Chrysotila carterae are also found to effectively bioremediate $\mathrm{CO}_{2}$ into organic biomass and generate inorganic $\mathrm{CaCO}_{3}$ as additional means of removing atmospheric $\mathrm{CO}_{2}$. However, the results of net energy analysis for $H$. pluvialis and a species of Nannochloropsis show a large energy deficit for both systems, due mainly to the energy required to culture and harvest. A better and cost efficient lipid extraction and transesterification technology is necessary for microalgal biodiesel systems to become viable from an energy standpoint (Razon and Tan 2011). This may be achievable if biodiesel production takes place within a biorefinery system coupled with wastewater treatment, carbon capture, and storage systems (Razon and Tan 2011; Roberts et al. 2013). 
Table 3 Some properties and lipid contents of microalgae strains

\begin{tabular}{|c|c|c|c|c|c|c|c|c|}
\hline Species & $\begin{array}{l}\text { SERI } \\
\text { designation }\end{array}$ & $\begin{array}{l}\text { Lipid \%dw } \\
\text { (nutrient } \\
\text { deplete) }\end{array}$ & $\begin{array}{l}\text { Lipid } \\
\% \text { dw (N } \\
\text { deficient) }\end{array}$ & $\begin{array}{l}\text { Lipid \% } \\
\text { dw (Si } \\
\text { deficient) }\end{array}$ & $\begin{array}{l}\text { Doubling } \\
\text { (1/day) }\end{array}$ & Temp. $\left({ }^{\circ} \mathrm{C}\right)$ & $\begin{array}{l}\text { Salinity } \\
(\mathrm{mS} / \mathrm{cm})\end{array}$ & Ref. \\
\hline A. hyalina & ENTOM3 & 22 & 30 & 37 & 2 & 20 to 35 & 10 to 60 & Akhtar and Amin (2011) \\
\hline A. coffeiformis & AMPHO1 & $4.1^{\mathrm{a}}$ & $13.6^{\mathrm{a}}$ & & 1.7 & 20 to $>35$ & $<10$ to $70^{\text {b }}$ & Adekunle et al. (2016) \\
\hline A. coffeiformis & AMPHO2 & & & & 2.48 & 30 to 35 & & Allnutt and Kessler (2015) \\
\hline A. cylindrica & & 4 to $7 / 4.9$ & 4.7 & & & & & Bahadar and Bilal Khan (2013) \\
\hline A. falcatus & ANKIS1 & $24.5^{\mathrm{a}}$ & $40.3^{\mathrm{a}}$ & & 2.89 & 18 to 31 & 1 to $10^{\mathrm{b}}$ & Adekunle et al. (2016) \\
\hline Boekelovia sp. & BOEKE1 & 23 to $29^{a}$ & $30.6^{\mathrm{a}}$ & & 3.43 & & & Adekunle et al. (2016) \\
\hline B. braunii & BOTRY1 & $44.5^{\mathrm{a}}$ & $54.2^{\mathrm{a}}$ & 46.3 & 1.8 & & & Adekunle et al. (2016) \\
\hline C. calcitrans & & 40 & & & & & & Bahadar and Bilal Khan (2013) \\
\hline C. gracilis & CHAET1 & 20.5 & & & 4.3 & & 15 to $35^{b}$ & Adekunle et al. (2016) \\
\hline C. muelleri & CHAET14 & 19 & 38 & 39 & The & 35 & & Allnutt and Kessler (2015) \\
\hline C. muelleri & CHAET58 & & & & 2.8 & 10 to 35 & 10 to 70 & Akhtar and Amin (2011) \\
\hline C. muelleri & CHAET61 & & & & 3.3 & 10 to 35 & 10 to 70 & Akhtar and Amin (2011) \\
\hline C. muelleri & CHAET63 & & & & 3.1 & 10 to 35 & 10 to 70 & Akhtar and Amin (2011) \\
\hline C. muelleri & CHAET9 & 17.8 & 28 & 25 & 4 & 10 to 35 & 10 to 115 & Akhtar and Amin (2011) \\
\hline Chaetoceros sp. & CHAET2 & 23 & 32.7 & & 4.3 & 20 to 40 & 10 to $40^{b}$ & Adekunle et al. (2016) \\
\hline C. applanata & & 18 & 33 & & & & & Bahadar and Bilal Khan (2013) \\
\hline C. reinhardtii & & 21 & & & & & & Bahadar and Bilal Khan (2013) \\
\hline C. ellipsoidea & CHLOR2 & 15.9 & 20.9 & & 5.3 & 20 to 35 & 10 to $40^{b}$ & Adekunle et al. (2016) \\
\hline C.emersonii & & 29 & 63 & & & & & Bahadar and Bilal Khan (2013) \\
\hline C. minutissima & & 31 & 57 & & & & & Bahadar and Bilal Khan (2013) \\
\hline C.protothecoides & & 13 & 23 & & & & & Bahadar and Bilal Khan (2013) \\
\hline C.pyrenoidosa & & 16 & 64 & & & & & Bahadar and Bilal Khan (2013) \\
\hline C. sorokiniana & & 18 & 18 & & & & & Bahadar and Bilal Khan (2013) \\
\hline Chlorella sp. & CHLOR1 & 10 & 34 to 48 & & 1.33 & 15 to 39 & 0 to $18^{\mathrm{b}}$ & Adekunle et al. (2016) \\
\hline Chlorella sp. & CHLOR3 & & & & 1.88 & 20 to $>40$ & 1 to $25^{\mathrm{b}}$ & Adekunle et al. (2016) \\
\hline C.vulgaris & & 25 & 42 & & & & & Bahadar and Bilal Khan (2013) \\
\hline C. cohnii & & 25 & & & & & & Bahadar and Bilal Khan (2013) \\
\hline C.acryptica & CYCLO4 & 12.1 & 11.3 & 13.2 & 1.6 & 10 to 35 & 10 to 70 & Akhtar and Amin (2011) \\
\hline Cyclotella sp. & CYCLO1 & $13.2^{\mathrm{a}}$ & $42.1^{\mathrm{a}}$ & $42^{\mathrm{a}}$ & 5.1 & 25 to $>35$ & 6 to $>45^{b}$ & Adekunle et al. (2016) \\
\hline Cylindrotheca & & 27 & 27 & & & & & Bahadar and Bilal Khan (2013) \\
\hline D. primolecta & & 23 & 14 & & & & & Bahadar and Bilal Khan (2013) \\
\hline D. salina & & 19 & 10 & & & & & Bahadar and Bilal Khan (2013) \\
\hline D. tertiolecta & & 15 & 18 & & & & & Bahadar and Bilal Khan (2013) \\
\hline E. oleoabundans & & 36 & 42 & & & & & Bahadar and Bilal Khan (2013) \\
\hline E. gracilis & & 20 & 35 & & & & & Bahadar and Bilal Khan (2013) \\
\hline H. carterae & & 20 & 14 & & & & & Bahadar and Bilal Khan (2013) \\
\hline I. galbana & ISOCH1 & 7.1 & 26 & & 2.83 & 16 to 34 & 5 to $60^{b}$ & Adekunle et al. (2016) \\
\hline M. subterranea & & 25 & 13 & & & & & Bahadar and Bilal Khan (2013) \\
\hline M. minutum & & 22 & 52 & & 2.84 & 25 to 30 & & Bahadar and Bilal Khan (2013) \\
\hline Monoraphidium sp. & MONOR1 & 23.4 & 29.4 & & 3.1 & & & Adekunle et al. (2016) \\
\hline Monoraphidium sp. & MONOR2 & & & & 5.8 & & & Akhtar and Amin (2011) \\
\hline Nannochloris & & 28 & 30 & & & & & Bahadar and Bilal Khan (2013) \\
\hline Nannochloropsis & & 31 & 41 & & & & & Bahadar and Bilal Khan (2013) \\
\hline N. salina & NANNO1 & $28.6^{\mathrm{a}}$ & $59.8^{\mathrm{a}}$ & & 1.05 & 17 to 32 & 6 to $60^{b}$ & Adekunle et al. (2016) \\
\hline Nannochloropsis sp. & NANNO2 & $31.4^{\mathrm{a}}$ & $64^{\mathrm{a}}$ & & 1.04 & 11 to 35 & 35 to $350^{b}$ & Adekunle et al. (2016) \\
\hline N. acceptata & NAVIC6 & 21.8 & 32.4 & 48.5 & 3.8 & 20 to 35 & 10 to 60 & Akhtar and Amin (2011) \\
\hline N. acceptata & NAVIC8 & 19.2 & 38.2 & 42.5 & 3.8 & 20 to 35 & 10 to 60 & Akhtar and Amin (2011) \\
\hline N.pelliculosa & & 27 & 45 & 34 & & & & Bahadar and Bilal Khan (2013) \\
\hline
\end{tabular}


Table 3 (continued)

\begin{tabular}{|c|c|c|c|c|c|c|c|c|}
\hline Species & $\begin{array}{l}\text { SERI } \\
\text { designation }\end{array}$ & $\begin{array}{l}\text { Lipid \%dw } \\
\text { (nutrient } \\
\text { deplete) }\end{array}$ & $\begin{array}{l}\text { Lipid } \\
\text { \%dw ( } N \\
\text { deficient) }\end{array}$ & $\begin{array}{l}\text { Lipid \% } \\
\text { dw (Si } \\
\text { deficient) }\end{array}$ & $\begin{array}{l}\text { Doubling } \\
\text { (1/day) }\end{array}$ & Temp. $\left({ }^{\circ} \mathrm{C}\right)$ & $\begin{array}{l}\text { Salinity } \\
(\mathrm{mS} / \mathrm{cm})\end{array}$ & Ref. \\
\hline N. saprophila & NAVIC24 & 24 & 51 & 49 & 3.1 & 10 to 30 & 10 to 70 & Akhtar and Amin (2011) \\
\hline N. communis & NITZS28 & & & & 2.7 & 10 to 30 & 10 to 70 & Akhtar and Amin (2011) \\
\hline N. dissipata & NITZS13 & 27.6 & 45.9 & 47.2 & 2.6 & 15 to 30 & 10 to 60 & Akhtar and Amin (2011) \\
\hline N. frustulum & & 26 & & & & & & Bahadar and Bilal Khan (2013) \\
\hline N.palea & & 47 & 40 & & & & & Bahadar and Bilal Khan (2013) \\
\hline N. dissipata & NITZS2 & $26.3^{\mathrm{a}}$ & $66^{\mathrm{a}}$ & & 1.32 & 20 to 30 & 6 to $45^{\mathrm{b}}$ & Adekunle et al. (2016) \\
\hline Nitzschia sp. & NITZS1 & 27 & & & & 10 to 44 & 30 to $90^{b}$ & Adekunle et al. (2016) \\
\hline O. pusilla & OOCYS1 & $10.5^{\mathrm{a}}$ & & & & 15 to 33 & 10 to $25^{\mathrm{b}}$ & Adekunle et al. (2016) \\
\hline Oscillatoria sp. & & 7 & 13 & & & & & Bahadar and Bilal Khan (2013) \\
\hline Ourococcus sp. & & 27 & 50 & & & & & Bahadar and Bilal Khan (2013) \\
\hline P. lutheri & & 36 & & & & & & Bahadar and Bilal Khan (2013) \\
\hline P. salina & & 31 & & & & & & Bahadar and Bilal Khan (2013) \\
\hline P. tricornutum & PHAEO1 & 38.2 & 56.8 & & 1.96 & $<15$ to 27 & $<20$ to $70^{b}$ & Adekunle et al. (2016) \\
\hline P. tricornutum & PHAEO2 & $19.7^{\mathrm{a}}$ & 23.2 & & 1.64 & & $\begin{array}{l}<8.5 \text { to } \\
70^{\mathrm{b}}\end{array}$ & Adekunle et al. (2016) \\
\hline P. tricornutum & & 21 & 26 & & & & & Bahadar and Bilal Khan (2013) \\
\hline P. purpureum & & 11 & & & & & & Bahadar and Bilal Khan (2013) \\
\hline P. parvum & & 30 & & & & & & Bahadar and Bilal Khan (2013) \\
\hline S. dimorphus & & 26 & & & & & & Bahadar and Bilal Khan (2013) \\
\hline S. obliquus & & 21 & 42 & & & & & Bahadar and Bilal Khan (2013) \\
\hline S. quadricauda & & 18 & & & & & & Bahadar and Bilal Khan (2013) \\
\hline S. gracile & & 21 & 28 & & & & & Bahadar and Bilal Khan (2013) \\
\hline S. costatum & & 16 & 25 & & & & & Bahadar and Bilal Khan (2013) \\
\hline S. maxima & & 7 & & & & & & Bahadar and Bilal Khan (2013) \\
\hline S. platensis & & 13 & 10 & & & & & Bahadar and Bilal Khan (2013) \\
\hline Synechococcus sp. & & 11 & & & & & & Bahadar and Bilal Khan (2013) \\
\hline Tetraselmis sp. & PLATY1 & $18^{\mathrm{a}}$ & $15^{\mathrm{a}}$ & $15^{\mathrm{a}}$ & 2.1 & & 15 to $>35^{b}$ & Adekunle et al. (2016) \\
\hline T. suecica & & 17 & 26 & & & & & Bahadar and Bilal Khan (2013) \\
\hline T.pseudonana & & 16 & 26 & & & & & Bahadar and Bilal Khan (2013) \\
\hline T. weissflogii & & 22 & 24 & & & & & Bahadar and Bilal Khan (2013) \\
\hline Tribonema sp. & & 12 & 16 & & & & & Bahadar and Bilal Khan (2013) \\
\hline
\end{tabular}

a afdw instead of $d w$

${ }^{b} \mathrm{TDS} / \mathrm{L}$ instead of $\mathrm{mS} / \mathrm{cm}$

Few concerted attempts have been made to test many strains of algae under similar conditions. Even the largest effort to categorize and record the lipid production of many algal strains, the US Department of Energy Aquatic Species Program (ASP), often operated under varying reactor conditions with tests in many different labs and varying results reported for similar strains of algae (Nrel 1998). Since then, several attempts have been made to continue categorizing and sorting strains based on lipid production rate and growth rate factors (Griffiths and Harrison 2009; Rodolfi et al. 2009) though much of the data come from the ASP or reactors of varying and unreported conditions. Along with these issues, the ASP did show that even algae of the same species can produce varying amounts of lipids depending on where the culture was taken and how it was preserved (Griffiths and Harrison 2009). Not only the reactor conditions and sample preservation methods, but also reporting methods in terms what are reported are extremely varied. For instance, lipid content is sometimes reported as a percentage of total weight and elsewhere as an ash-free dry weight.

\section{Wastewater as a source of nutrients and water for algal growth}

Wastewater in rural and other farming applications as well as municipal wastewater (MW) has potential as a source of the nutrients $\mathrm{N}$ and $\mathrm{P}$ needed for algal growth 
Table 4 Nitrogen and phosphorus contents of various wastewater. Sources (Cai et al. 2013; Christenson and Sims 2011; Muylaert et al. 2015)

\begin{tabular}{llll}
\hline Wastewater source & $\mathbf{N}(\mathbf{m g} / \mathbf{L})$ & $\mathbf{P}$ (mg/L) & $\mathbf{N}: P$ ratio (molar) \\
\hline Domestic & 20 to 85 & 5 to 20 & 11 to 13 \\
Pigs & 800 to 2300 & 50 to 320 & 12 to 17 \\
Beef cattle & 63 & 14 & 10 \\
Dairy cattle & 185 & 30 & 4 \\
Poultry & 800 & 50 & 32 \\
Coke production & 757 & 0.5 & 3000 \\
Tannery & 273 & 21 & 29 \\
Paper mill & 11 & 0.6 & 41 \\
Textile & 90 & 18 & 11 \\
Winery & 110 & 52 & 5 \\
Anaerobic digestion food & 1600 to 1900 & 300 & - \\
$\quad$ waste & & 182 & 2.9 \\
Olive mill & 530 & & \\
\hline
\end{tabular}

(Pienkos and Darzins 2009). Total N and P concentrations may vary between 10 and $100 \mathrm{mg} / \mathrm{L}$ (Table 4). The idea is attractive as a means to remove overabundant nutrients before their addition to rivers and lakes, thus preempting harmful microbial blooms. It also has the potential to supply algal farms with a large source of nonpotable water, which does not compete with municipal or conventional agricultural needs. Linking algal growth with water remediation also makes biofuel production more tenable by offsetting the high costs of wastewater treatment. The US has wastewater infrastructure investment requirements of $\$ 13$ billion to $\$ 21$ billion annually with an additional $\$ 21.4$ billion to $\$ 25.2$ billion required for annual operation and maintenance.

MW treatment goes through (i) primary treatment for the sedimentation of solid materials, (ii) secondary treatment for removing suspended and dissolved organic materials, and (iii) tertiary treatment for final treatment of water prior to discharge into the environment. The non-aqueous content of municipal wastewater $(\mathrm{MW})$ mainly consists of organic carbon (carbohydrates, fats, proteins, amino acids, and volatile acids), inorganics ( $\mathrm{Na}, \mathrm{Ca}, \mathrm{K}, \mathrm{Mg}, \mathrm{Cl}, \mathrm{S}$, phosphate, bicarbonate, ammonium salts, and heavy metals), coliform bacteria and toxic materials. The principal forms of nutrients are $\mathrm{NH}_{4}{ }^{+}$(ammonium) $\mathrm{NO}_{2}^{-}$(nitrite), $\mathrm{NO}_{3}^{-}$(nitrate) and $\mathrm{PO}_{4}{ }^{3-}$ (orthophosphate). MW treatment mainly involves removing the settable solids, which contain $40 \%$ of the biochemical oxygen demand (BOD) as well as various ions, heavy metals, organic compounds, toxicants, and soluble minerals. A significant portion of MW treatment is already done by naturally occurring, uncontrolled algae, e.g., Cholerella and Scenedesmus species
(Bhatnagar et al. 2010; Lau et al. 1995). Unicellular chlorophytes have been shown to be particularly tolerant to many wastewater conditions and very efficient at accumulating nutrients from wastewater (Aslan and Kapdan 2006).

Tertiary wastewater treatments currently exist but have variable nutrient removal efficiency, cleanup costs of secondary pollutants from chemical processes, and failure to effectively utilize available natural resources (Martínez 2000; Woertz et al. 2009). Microalgae are very effective at removing $\mathrm{N}$ and $\mathrm{P}$ from wastewater either in a free-swimming suspension or in an immobilized form. Various algal species provide very high $(>80 \%)$ removal of ammonia, nitrate, and total P from secondary treated wastewater (Martínez 2000; Pienkos and Darzins 2009; Woertz et al. 2009). C. vulgaris can remove over $90 \%$ of $\mathrm{N}$ and $80 \%$ of $\mathrm{P}$ content from settled sewage wastewater (Lau et al. 1995). The amounts of $\mathrm{N}$ and $\mathrm{P}$ required for algal growth can be estimated by mirroring the normal intracellular C:N:P ratio, known as the Redfield ratio (Kesaano and Sims 2014). Generally, many factors such as $\mathrm{N}$ and/or P limitation, silicon limitation, control of $\mathrm{pH}$, and low temperature can be used to increase oil accumulation, although their effectiveness depend on the strain and other culture conditions (Hena et al. 2015). Most municipal wastewater is known to have $\mathrm{C}: \mathrm{N}: \mathrm{P}$ ratios that differ substantially from Redfield values, resulting in $\mathrm{N}$ limitation and concomitantly leading to increased lipid production at the expense of growth (Griffiths and Harrison 2009; Kesaano and Sims 2014). Algae supplemented with $\mathrm{CO}_{2}$ have been shown to remove $>96 \%$ of orthophosphate and ammonia from dairy farm wastewater with a holding time of 12 days, while maintaining lipid content between 14 and $29 \%$. A volumetric productivity of $11,000 \mathrm{~L} / \mathrm{ha} /$ year is postulated based on the maximum lipid yield (Woertz et al. 2009). Hena et al. (2015) also demonstrated nutrient removal of $98 \%$ from treated dairy farm wastewater using a consortium of native strains while achieving a final lipid content of $17 \%$.

Utilization of microalgae for the biological tertiary treatment of municipal wastewater is limited by the recovery of biomass from the treated effluent and the land-space requirements. Compareing wastewater treatment plants with land available for the growth of algae would be valuable to check the efficacy of a paired wastewater-algae system. Analysis of the wastewater systems in Kansas has shown that a pairing of wastewater treatment and algae in rural areas would be limited by the wastewater availability, while MW treatment pairings would most likely be limited by land availability. Overall, a pairing like this in Kansas could provide 29\% of liquid fuel demand (Kesaano and Sims 2014). Also valuable is $\mathrm{CO}_{2}$ sequestration with algal growth (Demirel 2016). One 


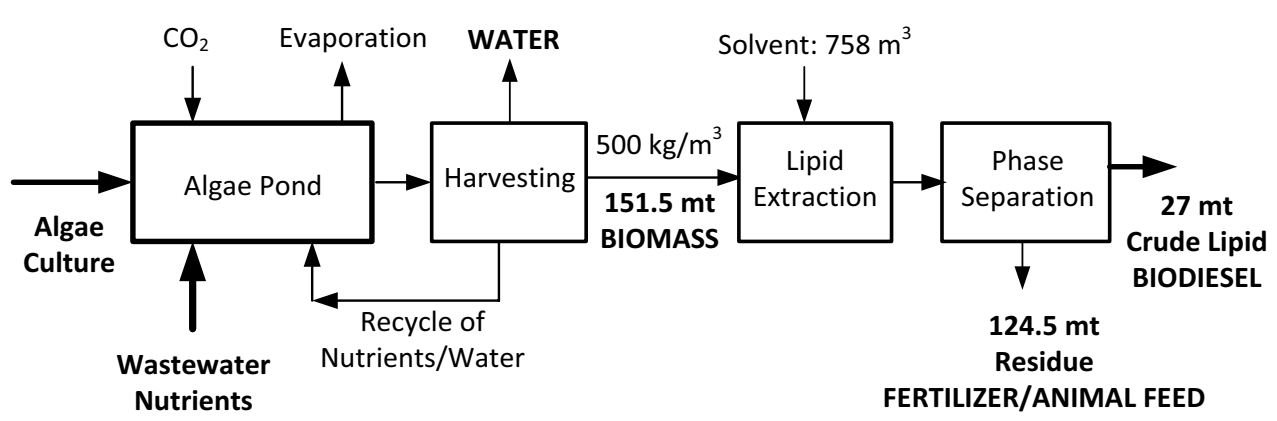

Fig. 1 An approximate mass balance for biomass to biodiesel and fertilizer/animal feed supply chain (Harun et al. 2013)

of the limitations of algal growth is the availability of $\mathrm{CO}_{2}$ at atmospheric concentrations. This can be overcome by pumping $\mathrm{CO}_{2}$ into the reactor from a power plant or ethanol plant (Sturm and Lamer 2011).

A synergistic model for an algae-based biofuel production coupled with the bioremediation of municipal and agricultural wastewaters addresses several economic bottlenecks to earlier algal systems and promotes valueadded products, including a high-quality effluent in addition to biodiesel to improve the economic feasibility of algal biofuels (Lyon et al. 2015; Muylaert et al. 2015). Large wastewater treatment plants are located adjacent to dense urban landscapes and process around 200,000$1,000,000 \mathrm{~L} /$ day. Small plants processing around 2000$40,000 \mathrm{~L} /$ day are located away from populated areas, which may accommodate algae culturing and growing ponds. Use of wastewaters for cultivation of microalgae can also substantially reduce the cost of production and reduce the requirement for freshwater. Figure 1 shows a block flow diagram for algal lipid production systems with nutrients recovered from wastewater and solvent technology for lipid extraction (Harun et al. 2013).

\section{Cultivation using wastewater resources}

Woertz et al. (2009) investigated the lipid productivity and nutrient removal by green algae grown during treatment of dairy farm and MW supplemented with $\mathrm{CO}_{2}$. Peak lipid content ranges from 14 to $29 \%$, depending on dairy wastewater concentration with a volumetric productivity of $17 \mathrm{mg} / \mathrm{L}$ day of reactor and a real productivity of $2.8 \mathrm{~g} / \mathrm{m}^{2}$ day, which would be equivalent to $11,000 \mathrm{~L} /$ ha year (1200 gallons/acre year) if sustained year-round. After 12 days, ammonium and orthophosphate removals are measured $96 \%$ and $>99 \%$, respectively. With MW treated in semi-continuous indoor cultures, maximum lipid productivity is around $24 \mathrm{mg} / \mathrm{L}$ day, observed in the 3-day hydraulic residence time cultures. A greater than $99 \%$ removal of ammonium and orthophosphate is achieved. $\mathrm{CO}_{2}$-supplemented algae cultures can simultaneously remove dissolved $\mathrm{N}$ and $\mathrm{P}$ to low levels, while generating a biomass useful for production of biofuels and bioproducts (Woertz et al. 2009). Supplying nutrients from wastewater could help to offset the costs of an algae-based biofuel plant as well as wastewater treatment and lead to a reduced environmental footprint (Rawat et al. 2011). However, this restricts production of algae to areas near wastewater treatment plants (Kesaano and Sims 2014).

Sturm and Lamer (2011) have used four pilot-scale reactors (2500 gallons each) fed with wastewater effluent from a conventional activated sludge process for 6 months, and the data have been used to estimate an energy balance for treating the total average 12 million gallons/day processed by the wastewater treatment plant. Since one of the most energy-intensive steps is the harvesting of algal cultures, several thickening and dewatering processes have been compared. This analysis also includes the energy offset from removing nutrients with algal reactors rather than the biological nutrient removal processes typically utilized in MW treatment. The results show that biofuel production is energetically favorable for open-pond reactors utilizing wastewater as a nutrient source. In another study, Fortier and Sturm (2012) have used four algal bioreactors fed continuously with MW effluent over a 6-month period. Algal biomass production ranged from 0.78 to $15.9 \mathrm{~g}$ dry weight $/ \mathrm{m}^{2}$ day over the experimental period. Algal reactors removed 19\% of dissolved $\mathrm{N}$ and $43 \%$ of dissolved $\mathrm{P}$ from wastewater effluent. A stoichiometric analysis of particulates reveals that algal biomass has far lower C:P ratios $(67: 1)$ and N:P ratios $(6: 1)$, but higher $\mathrm{C}: \mathrm{N}$ ratios $(17: 1)$ than the Redfield values. A sustainable biofuel production require cultivation of microalgae with high lipid yield using nutrients recovered from wastewater and waste $\mathrm{CO}_{2}$ from such as flue gas of a coal or natural gas-fired power plant (Rodolfi et al. 2009).

Microorganisms selected for their oil-producing capabilities could increase biodiesel production to the 10 
billion gallon mark, which is more than three times the current biodiesel production capacity in the US Currently, the estimated cost of production is around $\$ 3.11$ / gallon of biodiesel. To be competitive, this cost should be reduced to levels that are at or below the current petro diesel costs of $\$ 3.00 /$ gallon; biodiesel production from wastewater sludge could be one way of achieving this target in the long run (Kargbo 2010).

Although the majority of algal production reactors use suspended cultures, the use of attached cultures may offer several advantages (Kesaano and Sims 2014). Hyperconcentrated cultures can have $>1.5 \mathrm{~g}$ biomass $/ \mathrm{L}$, accelerate removal of nutrients compared to normal cultures, and require smaller pond areas or permit a reduced residence time. Immobilized and hyperconcentrated cultures on a suitable support may simplify the harvesting of biomass because of the entrapment of cells and increased retention time in the reactor. The feasibility of using immobilized and hyperconcentrated microalgae and cynobacteria for removing nutrients from high volume effluent discharges needs to be confirmed. Biofilm or attached systems, where microalgae grow on a substrate, reduce energy consumption, water volume, and, hence, ease of harvesting; however, they have higher capital cost than open ponds. For example, Phormidum laminosum immobilized on polymer foam can remove nitrate, in a continuous flow system with uptake efficiency above $90 \%$ (Travieso et al. 1992). More research is needed in mass transport, algal growth rate, and other important information to understand the efficacy of biofilm/substrate algae growth systems (Kesaano and Sims 2014).

Concentrated inoculum can have $1 \times 10^{7}$ cells/L, while low density inoculum $5 \times 10^{5}$ cells $/ \mathrm{mL}$. Effective wastewater growth and nutrient removal are not significantly dependent on starting cell density. In the wastewater generated from the sludge centrifuge with total $\mathrm{N}$ of $131.5 \mathrm{mg} / \mathrm{L}$ and total P of $2015 \mathrm{mg} / \mathrm{L}$, the cells are able to grow. Chlorella minutissima can grow well in high concentration of raw sewage and dominate the subsequent pond stages in the oxidation pond system. This strain is heterotrophic in the dark and mixotrophic in the light. It can utilize either ammonia or nitrate as $\mathrm{N}$ source with a growth rate of $379 \mathrm{mg} / \mathrm{L}$ after 10 days (Bhatnagar et al. 2010).

\section{Some challenges in algal cultivation using wastewater resources}

The integration of microalgal cultivation and wastewater treatment processes has major challenges (Pienkos and Darzins 2009) mainly because of natural interactions among biology, ecology, and technology.

Microalgae species: There is a need to cultivate an appropriate single or multi-species community of strains to increase the oil yield. The ability of different algal species to tolerate a particular wastewater conditions varies (Griffiths and Harrison 2009; Hu et al. 2008).

Spatial and temporal mismatches between algae growth and wastewater resources: Microalgae farms should be close to the wastewater and waste $\mathrm{CO}_{2}$ sources and availability of wastewater based nutrients and microalgae growth should match without excessive fluctuations in growth. The consumption of $\mathrm{N}$ and $\mathrm{P}$ by microalgae is known to occur in relative proportionality defined by the Redfield ratio that is a molar ratio of N:P of $16: 1$. Higher ratios indicate that availability of $\mathrm{P}$ is limiting the growth of microalgae (Geider and La Roche 2002). No nutrient limitation leads to high content of protein, while nutrient limitation does lead to high carbohydrate or lipids, depending on the species of microalgae and degree of limitations. If $\mathrm{N}$ or $\mathrm{P}$ is limiting, lipid or carbohydrate is accumulated. In cold temperatures microalgae productivity is low, and it may be necessary to close microalgae farms for months. High temperature may also limit growth.

Space for microalgae cultivation: The minimum economically productive size of a microalgae farm would be around 10 ha, theoretically producing 300 ton dry microalgae biomass/ha year and consuming 27 ton N/year serving a population of 9000 (Muylaert et al. 2015). An open raceway pond with biomass containing $7 \% \mathrm{~N}$ and $1 \% \mathrm{P}$, at $0.5 \mathrm{~g} / \mathrm{L}$ requires a minimal nutrient concentration of $5 \mathrm{mg} \mathrm{P} / \mathrm{L}$ and $35 \mathrm{mg} \mathrm{N} / \mathrm{L}$. In an optimized largescale operation, the culture medium should be repeatedly recycled until all nutrients were fully consumed.

Bioavailability of nutrients to microalgae in different types of wastewater: The bioavailability of $\mathrm{P}$ may vary between 4 and $81 \%$ depending on the wastewater source (Muylaert et al. 2015). Limited information is available about the bioavailability of organic $\mathrm{N}$ forms. Bioavailability of free amino acids and nucleotides to microalgae is high. Peptides or proteins have slightly lower bio-availability (Muylaert et al. 2015). Bio-availability of organic nitrogen also differs by algae strain, emphasizing the value of matching strains with available wastewater resources (Davis et al. 2012). Part of the organic $\mathrm{N}$ in wastewater is slowly made available by bacteria that live in symbiosis with microalgae (Muylaert et al. 2015).

Losses of nutrients from wastewater: Wastewater $\mathrm{pH}$ can be high due to photosynthetic depletion of $\mathrm{CO}_{2}$ from the microalgae culture medium, which may lead to volatilization of ammonia converted from ammonium or precipitation of $\mathrm{P}$. The resulting displacement of $\mathrm{N}$ can cause eutrophication in the surrounding landscape through $\mathrm{N}$ deposition. Maintaining the $\mathrm{pH}$ of the culture medium at 8 by addition of $\mathrm{CO}_{2}$ may prevent ammonia volatilization. At high $\mathrm{pH}$, phosphatases precipitate as calcium 
phosphate when $\mathrm{Ca}$ concentrations are high or struvite when ammonium and magnesium concentrations are high (Beuckels et al. 2013). Phosphate loss from the wastewater causes additional turbidity in medium and reduces the growth of microalgae biomass (Belay 1997.)

Biomass growth inhibition: Contaminants, such as heavy metals, persistent organic pollutants, and surfactant can inhibit microalgae growth. Biotic factors that may impact negatively on growth include pathogenic bacteria or predatory zooplankton. Starting density of microalgae in the wastewater is also likely to be critical factor (Lau et al. 1995). Free ammonia, for instance, is commonly toxic to algae at both high and low pH levels (Peccia et al. 2013). The cell wall of microalgae is often rich in carboxyl, amine hydroxyl, or sulfate groups, which are anionic and can bind metals through ion exchange. Metals used for flocculating microalgae are also known to remain in the protein rich residue after extraction of lipids. Wastewater can also contain microbial contaminants such as parasite cysts, infectious bacteria, or viruses that interfere with the use of biomass as animal feed. Wastewater can be pre-treated with oxidizing agents such as sodium hypochlorite, ozone, hydrogen peroxide, or by coagulant, flocculants, or adsorbents (Allnutt and Kessler 2015; Markou et al. 2015). Separating nutrients from wastewater by dialysis membrane (Blais et al. 1984) or by sorbing onto zeolites and releasing them into fresh medium may be helpful (Markou et al. 2015).

Biological contamination of microalgae cultures: Wastewater contains spores, dispersal stages of herbivores of microalgae such as microcrustaceans (e.g., Daphnia spp.), rotifiers, or ciliates. If Daphnia invades the system, it can quickly reduce microalgae growth (Cauchie et al. 2000; Kazamia et al. 2012; Wang et al. 2013). Daphnia can easily be removed due to its large size using a mesh; however, the smaller herbivores cannot be easily controlled by simple screening. The risk of contamination can be limited by sterilizing the wastewater, or by chemical disinfection. The cost of disinfection could be too high when microalgae are converted into low-value commodity production, such as fuel or animal feed. Consortia of microalgae may be more resistant to the impact of small herbivores as well as be more efficient converting nutrients into biomass than that of monospecific cultures. If consortia contain toxic species such as cyanobacteria, the biomass cannot be used for human or animal food. However, it is more difficult to control the biochemical composition of the biomass in mixed consortia than in pure cultures as some species may produce carbohydrates, while others produce lipids.

Heavy metals: Microalgae can efficiently absorb heavy metals (Al, Au, Co, Cd, Cr (II, III, IV), $\mathrm{Cu}, \mathrm{Fe}, \mathrm{Hg}, \mathrm{Ni}, \mathrm{Pb}$, $\mathrm{Zn}$, and $\mathrm{U}$ ) from wastewaters even in low concentrations
(Wijffels et al. 2010). Metal sorption involves binding on the cell surface and to intracellular ligands. Carboxyl group is most important for metal binding. Concentration of metal and biomass in solution, $\mathrm{pH}$, temperature, cations, anions, and metabolic stage of the organism affect metal sorption. Algae can effectively remove metals from multi-metal solutions (Mehta and Gaur 2005).

\section{Ecology}

Optimum resources for algal cultivation

Open ponds are cost-effective system and there is an important role for aquatic ecologists to help improve the operation and performance of the engineered biosystems for algal biomass cultivation (Smith and Mcbride 2015). The availability of nutrients can be limiting for the productivity and should be optimized if algae-derived biofuels are to be sustainable. Algal biomass at a given concentration of total phosphorus increases with an increase in the total N:P ratio (Smith and Mcbride 2015). The core principles of nutrient physiology and ecological stoichiometry can help to determine the effects of nutrient supply ratios on biomass yields, species composition and quality of biomass produced. The specific growth rate of a cultivated algae is a function of the intracellular nutrient quota and the inverse of this cell quota is the nutrient use efficiency (NUE) (1 mg of algal biomass produced per $1 \mathrm{mg}$ of cellular nutrients). The value of NUE provides a direct, quantitative measure of the resource demands of algal production and thus the resource-associated economic costs of biomass cultivation. The magnitude of NUE and the Redfield Ratio C:N:P stoichiometry for the elemental content of algae of 106:16:1 are highly sensitive to variations in local environmental conditions, such as light and temperature (Smith and McBride 2015; Bartley et al. 2016).

\section{Contamination}

Because of potential invasions by other species from the local and regional environment, contamination of openpond systems will be certain during long-term continuous operation. It will be essential to regulate top-down interactions in large-scale biomass cultivation systems to avoid losses to herbivores, and to maximize algal biomass yields (Nalley et al. 2014). Nutrient enrichment has strong effects on the incidence and the severity of aquatic diseases and the use of chemical agents may be one potential solution to this dilemma. However, their intensive use will add to operating expenses, and many chemical control strategies have not been successful at scale for extended periods of time in open ponds used for biofuel production. Aquatic ecologists would evaluate the effects of both species diversity and genetic diversity 
on disease resistance and on the potential value of crop rotation. This helps in reducing disease risk and disease intensity in large-scale algal biomass cultivation systems (Mooij et al. 2015).

\section{Community of species}

Carefully screened mixed species communities, for example, the presence of heterotrophic flagellates (micrograzers) may enhance nutrient availability and, thus, may increase microalgal yield. Polycultures can exhibit significant temporal variations in crop species composition, yield and quality, resource limitation, the hydraulic retention time of the system and local variations in temperature and salinity. Researching the relative costs and benefits of monoculture versus polyculture helps to understand if temporal variability in aquatic community structure can be predicted and controlled and if crop rotation in space and in time helps to reduce or stabilize this temporal variability (Smith and Mcbride 2015).

\section{Frequency of algal crop harvesting}

The cost of resource per unit volume of algal production increases with dilution rate as each algal cell contains a cell quota of essential chemical elements such as carbon, nitrogen and phosphorus. At the same time, the continuous application of fertilizers for food and energy production has the potential to result in the nutrient pollution of global terrestrial, aquatic and atmospheric environments. The integration of direct experimentation with mathematical modeling efforts designed to understand different harvesting strategies under a wide variety of environmental conditions would be beneficial for algal-based biofuels and bioproducts. In particular, the principles of ecology can control and predict the internal biological dynamics and biomaterial outputs in a reliable operation of large algal cultivation systems. Optimum harvesting theory may be helpful to the sustainable future production of algal biofuels and bioproducts (Bartley et al. 2016; Smith and Crews 2014).

\section{Engineering}

\section{Algal-based biofuel and bioproduct processes}

Allnutt and Kessler (2015) reviewed some of the most promising microalgae biomass growth technologies for sustainable microalgae production. Figure 2 shows variety of biofuel and bioproduct productions from photoautotrophic algae cultivation by considering the possible conversion processes other than transesterification. Following growth, the algae undergo harvesting, extraction, and various conversion processes of esterification, anaerobic fermentation, gasification, pyrolysis, and hydrothermal liquefaction. The number and intensity of post harvesting processes depend on the desired product and will have positive impact on the feasibility of algal-based productions (Ferrell and Sarisky-Reed 2010; Halim et al. 2013).

Algae growth, the lipid content, and overall cost are defined by the method of cultivation. Algae strain, the source of nutrients for the algae, and the type of reactor that the algae are grown in are three of the most influential factors. Open-pond and photobioreactors are the two major types of reactor seen as the dominant possibilities for algae growth with targeted productivity of $25 \mathrm{~g} /$ $\mathrm{m}^{2}$ day or higher based on the nutrient requirements. For lower cost and GHG emissions, nutrients fixed in the biomass should be recycled back to growth medium (Davis et al. 2016).

The 2012 National Research Council's report on sustainable development of algal biofuels concluded the need for research, development, and demonstration of algal strain selection, an EROI that is comparable to other transportation fuels, and the use of wastewater for cultivating algae for fuels (National Research Council 2012a). EROI estimates the quality of the biofuel as the ratio of the energy delivered by the biofuel to society and the energy consumed in the production and delivery of the biofuel. Energy payback period would be estimated as the time required for a biofuel to generate the same amount of energy that went into the creation, maintenance, and disposal of that fuel (Hall et al. 2014).

\section{Reactors}

Open tanks with natural circulation are mostly replaced by the more efficient raceway system, which are closed shallow pools to maximize light penetration with water circulated and mixed by a paddle wheel. Raceways are simple systems and require low construction cost (Richardson et al. 2012). One drawback is the risk of contamination that may require the need to keep the raceways in relatively extreme conditions, usually alkaline or salinity that may limit the type of strains (Bahadar and Bilal Khan 2013). Another drawback is the decreased lipid content (10\%) compared to closed reactors (50-60\%). Sturm and Lamer (2011) used four pilot-scale reactors of 2500 gallons each fed using wastewater effluent from an activated sludge process for 6 months and used the data to estimate an energy balance limited to direct combustion of algal biomass.

Closed photobioreactor (PBR) systems come with a wide range of possible shapes and supply a high-quality starter culture into an open-pond system. Flat plate reactors have the advantage of good temperature control and low fouling possibilities, but due to their shape and volumetric limitations are harder to scale up than 


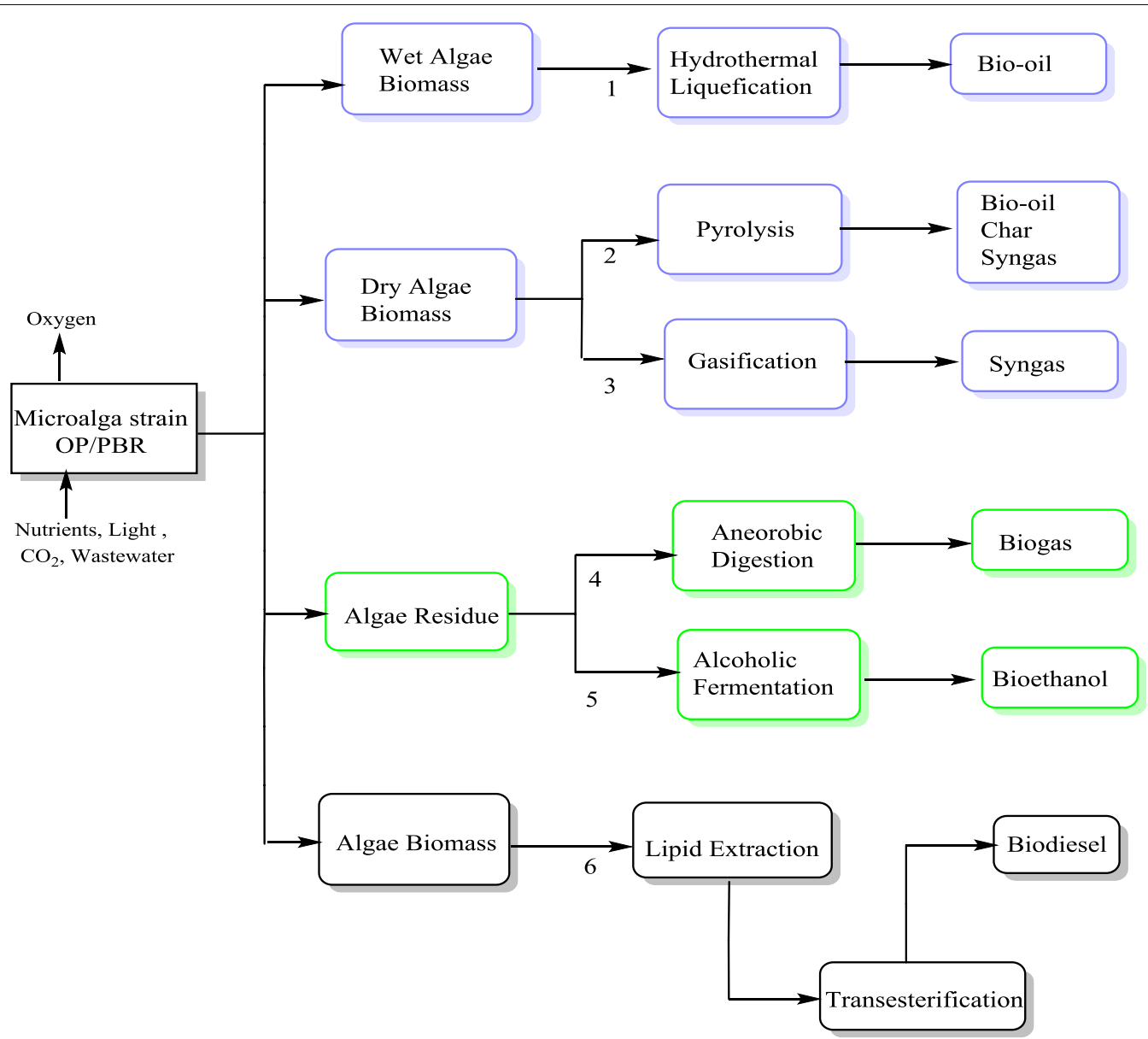

Fig. 2 Some possible algal-based processes for biofuel and bioproduct productions. OP open pond, PBR photo bioreactor

tubular reactors. Tubular reactors are cylindrical pipes made out of transparent material in which pumping the growth medium cause constant mixing and a well-controlled environment. Tubular systems have good circulation, excellent surface area-volume ratios, and are easy to scale up (Molina Grima et al. 2003).

Hundreds of hectares of PBRs would not be economically feasible nor sustainable due to their high starting cost and energy needs. The open high-rate ponds offer the lowest total cost and energy consumption for largescale biomass production with low energy and lowcost methodologies for water removal. PBRs provide the microalgae culture with a controlled environment to maximize the productivity (Bahadar and Bilal Khan 2013) by preventing the invasion of local flora and fauna, a risk for open raceway (Cauchie et al. 2000). Along with the protection from competing organisms, the evaporative water loss from PBRs is much lower than raceway ponds. Perhaps the greatest, often neglected, advantage of PBR technology is the decreased land use compared to the very high surface areas required by raceway ponds, which is a limiting factor.

Table 5 summarizes some of the differences between closed and open bioreactor. While there are many advantages for the PBRs, the major drawback is the high cost, which ranges from nearly threefold to an order of magnitude higher than raceway pond systems (Richardson et al. 2012 ) to differences of an order of magnitude (Lyon et al. 2015). This increased cost is mainly due to the additional expense of the materials needed for construction, as well due to cooling and pumping needs. However, it is worth noting that improved reactor design could help to mitigate some of these costs and greatly improve the outlook of PBR use in industry (Dillschneider and Posten 2013).

\section{Harvesting}

Centrifugation and sedimentation may be costly for the production of biofuel and bioproducts. Table 6 shows the total primary energy input of harvesting and downstream steps to determine the energy efficiency of the process (Ketzer et al. 2018). Allnutt and Kessler (2015) 
Table 5 Comparison of raceways and photobioreactors (Bahadar and Bilal Khan 2013; Dillschneider and Posten 2013; Lyon et al. 2015; Richardson et al. 2012)

\begin{tabular}{|c|c|c|}
\hline Reactor type & Advantages & Disadvantages \\
\hline Raceway & $\begin{array}{l}\text { Lower capital cost } \\
\text { Lower annual cost }\end{array}$ & $\begin{array}{l}\text { Risk of contamination } \\
\text { Lower productivity }\end{array}$ \\
\hline $\begin{array}{l}\text { Photobioreactors: tubular, helical, tubularverti- } \\
\text { cal, flat panel, cuboidal, stirred tank, air lift, } \\
\text { bubble column tubular }\end{array}$ & $\begin{array}{l}\text { Effective light use } \\
\text { Little risk of contamination } \\
\text { More controlled environment } \\
\text { Higher productivity and cell densities } \\
\text { High gas transfer coefficients } \\
\text { Easy } \mathrm{CO}_{2} \text { supply } \\
\text { Lower land use } \\
\text { Lower water loss }\end{array}$ & $\begin{array}{l}\text { Estimated } 2.6 \text { times the capital cost of Raceway ponds } \\
\text { Estimated } 1.5 \text { times the annual operating cost } \\
\text { Risk of oxygen oversaturation } \\
\text { Difficult to scale up } \\
\text { Increased shear stress by pumps }\end{array}$ \\
\hline
\end{tabular}

Table 6 Total energy input of Harvesting and Downstream processes

\begin{tabular}{lcl}
\hline References & $\begin{array}{l}\text { Total energy input (MJ/kg } \\
\text { dry algae) }\end{array}$ & Comments \\
\hline Campbell et al. (2011) & 2.625 & Diesel tractor used in harvesting algae \\
Clarens et al. (2009) & 14.79 & Harvested via flocculation and centrifugation \\
Collet et al. (2011) & 5.5 & Harvested in two steps. Natural settling and centrifugation \\
Jorquera et al. (2010) & 5.17 & According to Clarens et al. (2009) \\
Khoo et al. (2011) & 2.73 & Air sparging-assisted coagulation flocculation (ASACF) process is used in harvesting \\
Lardon et al. (2009) & 24.08 & Low N culture. Harvested via flocculation \\
Lardon et al. (2009) & 23.89 & Normal N culture. Harvested via flocculation \\
Liu and Ma (2009) & 3.75 & Concentration \\
Razon and Tan (2011) & 35.56 & Harvesting process via thickener, microfiltration and bead mill \\
Yanfen et al. (2012) & 41.13 & Harvested by sedimentation and centrifugation \\
Resurreccion et al. (2012) & 44.73 & OP-FW configuration. Primary dewatering \\
Resurreccion et al. (2012) & 32.44 & OP-BSW configuration. Primary dewatering \\
Frank et al. (2013) & 0.23 & Harvested by bio-flocculation, dissolved-air flotation, and centrifugation. \\
Bennion et al. (2015) & 12.3 & Dewatered via membrane filtration system and centrifugation. \\
Jorquera et al. (2010) & 9.02 & According to Clarens et al. (2009) \\
Resurreccion et al. (2012) & 32.04 & PBR-FW configuration. Primary dewatering \\
Resurreccion et al. (2012) & 18.26 & PBR-BSW configuration. Primary dewatering \\
\hline According to Kezret &
\end{tabular}

According to Ketzer et al. (2018). The total energy input varies with an approximate average of $28 \mathrm{MJ} / \mathrm{kg}$ dry algae

discussed the historical approaches and recent advances while comparing and contrasting the different methods with an engineering estimate of comparative costs. First, the algae must be concentrated by means of filtration, centrifugation, and flocculation (Mercer and Armenta 2011). Following this step, the algae may need to be dried, milled or pretreated in some other way such as microwaving, chemical treatment or milling to improve lipid extraction (Harun et al. 2013). After harvesting a $20 \mathrm{wt} \%$ solids biomass is generally considered ready for most downstream processing steps (Davis et al. 2014). Flocculation may be a cost-effective method (Vandamme et al. 2013).

Primary dewatering is typically achieved through flocculation followed by separation via settling or flotation. Flocculants can limit the reuse of de-oiled flocculated microalgae. Natural flocculation of microalgae in response to changes in $\mathrm{pH}$ and water hardness, if controlled, might lead to less-expensive "flocculants-free" dewatering. Auto-flocculation is driven by a coordination between microalgae, $\mathrm{Ca}^{2+}$ and $\mathrm{Mg}^{2+}$, and/or mineral surface precipitates of calcite, $\mathrm{Mg}(\mathrm{OH})_{2}$, and hydroxyapatite that form primarily at $\mathrm{pH}>8$. Combining surface complexation models that describe the interface of microalgae allows optimal auto flocculation conditions-for example, $\mathrm{pH}, \mathrm{Mg}, \mathrm{Ca}$, and $\mathrm{P}$ levels that must be identified for a given culture medium. This may have a large impact on cost of algal biomass production. 


\section{Lipid extraction}

Some of the chemical solvents for lipid extraction are 1-butanol, isopropanol/hexane, hexane, ethanol, chloroform/methanol, hexane/ether (Bahadar and Bilal Khan 2013). A number of nonpolar organic solvents such as hexane, or chloroform can diffuse through the cell walls and separate lipids into an organic phase, leaving other solutes in an aqueous phase (Halim et al. 2013; Suali and Sarbatly 2012). Valdez et al. (2011) used both nonpolar solvents (hexadecane, decane, hexane, and cyclohexane) and polar solvents (methoxycyclopentane, dichloromethane, and chloroform). Hexadecane and decane provide the highest gravimetric yields of bio-oil; but these crude bio-oils had a lower carbon content (69 wt \% for decane) than did those recovered with polar solvents such as chloroform (74 wt \%) and dichloromethane (76 wt\%).

Mixtures of multiple organic solvents have shown to be more effective than a single solvent. Possible solvent mixtures are chloroform/methanol $(2: 1 \mathrm{v} / \mathrm{v}$ with highest lipid extraction), hexane/isopropanol (3:2 v/v), dichloroethane/methanol (1:1 v/v), and acetone/dichloromethane $(1: 1 \mathrm{v} / \mathrm{v})$. Valdez et al. (2011) quantified the amount of 19 different individual molecular components in the crude bio-oil; fatty acids are the most abundant components beside some aromatic and sulfur- and nitrogen-containing compounds. The amount of free fatty acids in the crude bio-oil significantly depends on the solvent used, with polar solvents recovering more fatty acids than nonpolar solvents. The bio-oil recovered with chloroform, for example, had a fatty acid content equal to $9.0 \mathrm{wt} \%$ of the initial dry algal biomass. Overall, solvent extraction shows that: (i) nonpolar solvents extract bio-oils with lower carbon content and thus lower energy density, (ii) polar solvents extract lower yields but a much higher fatty acid content, (iii) solvent choice affects the carbon content of the dissolved aqueous solids, (iv) the polar solvents produced solids are lower in both carbon and nitrogen relative to those recovered with nonpolar solvents.

Weakening or breaking algal cell walls by physical, chemical, mechanical, and biological pre-treatments can enhance the efficiency of lipid extraction (Ghasemi Naghdi et al. 2016; Harun et al. 2013). Mixtures of polar and non-polar solvents (i.e., hexane ethanol) are especially beneficial for wet biomass as the polar aspects acts to bridge the water layer surrounding the cells thus enabling penetration by the non-polar aspects. Cost, safety, and environmental concerns are the main limitations for organic-based solvents.

20-30 min of microwave treatment has been shown to increase solvent extraction from a $52 \mathrm{wt} \%$ oil yield to a 77 wt\% oil (Balasubramanian et al. 2011). Using ultrasonic waves, the time taken for a similar solvent removal can be reduced by as much as $80 \%$ (Ghasemi Naghdi et al.
2016; Suarsini and Subandi 2011). Microwave-assisted extraction may reduce the cost of dewatering and extracting of dry algae. As heat is produced, water vapor formed within the cell ruptures the cell wall increasing the extraction yield (Bahadar and Bilal Khan 2013; Balasubramanian et al. 2011; Lee et al. 2010). However, at scale-up, the cost may be limiting factor for this application. Rarefaction and compression waves induced by the ultrasound (above audible frequency, e.g., $19 \mathrm{kHz}$ ) lead to the formation of cavities leading to growth and implosive collapse of bubbles in a liquid causing intense local heating ( $5000 \mathrm{~K})$, high pressures $(\sim 1000 \mathrm{~atm})$, and high shear forces (Bendicho et al. 2012). Ultrasound-assisted extraction can be cost effective and reduce the extraction time compared with conventional mechanical disruption, since the cavitation by the ultrasonic wave can rupture the cell wall and help improve the solvent extraction (Mercer and Armenta 2011; Metherel et al. 2009). A sudden drop in osmotic pressure can similarly burst wet algae cells and can increase lipid recovery up to two times with polar and non-polar solvent, depending on the cell wall properties (Mercer and Armenta 2011; Yoo et al. 2012). Enzymatic treatment to disrupt cell walls of wet algae is also a promising alternative. This method causes minimal damage to lipid and hydrocarbons, but requires long cycle time and dependent on the strains being disrupted (Ghasemi Naghdi et al. 2016; Mercer and Armenta 2011). In contrast, the application-free nitrous acid $\left(\mathrm{HNO}_{2}-\mathrm{N}\right.$, renewable chemical) is another example of a pretreatment method that can lead to oxidative damage of cellular molecules prior to extraction, thus reducing the final quality of the fuel (Bai et al. 2014). Aqueous pores in the cell walls can be created by applying a pulsed electric field in the cells. This increases mass transfer and hence improves the lipid extraction (Sommerfeld et al. 2008). Table 7 compares some of the assisted solvent extraction techniques. Supercritical $\mathrm{CO}_{2}$ extraction can also be used as an alternative and green solvent to extract triglyceride acid (TGA) and other lipids faster. However, the cost of technique is very high (Bahadar and Bilal Khan 2013). Santana et al. (2012) studied the performance of Supercritical $\mathrm{CO}_{2}$ extraction and hexane extraction based on the yield and fatty acid compositions of the lipids extracted from microalgae Botryococcus braunii concluding that the conventional extraction process is slightly faster. Sahena et al. (2009) compared traditional solvent extraction method with supercritical fluid extraction as shown in Table 8.

The quality of the biodiesel product can be improved through degumming for an accepted level of gums and metals removal. The most cost-effective method is simple water degumming, which can reduce the $\mathrm{P}$ from 1148 to $19 \mathrm{ppm}$ and $\mathrm{Ca}$ from 92 to $11 \mathrm{ppm}$. Post extraction 
Table 7 Comparison of different lipid extractions methods (Ghasemi Naghdi et al. 2016; Mercer and Armenta 2011; Mubarak et al. 2015; Sahena et al. 2009)

\begin{tabular}{|c|c|c|}
\hline Extraction method & Advantages & Limitations \\
\hline Ultrasound-assisted & $\begin{array}{l}\text { Reduced extraction time } \\
\text { Great penetration of solvent into the cellular materials, } \\
\text { low set-up costs } \\
\text { Environmentally friendly and safe } \\
\text { Reduced solvent consumption }\end{array}$ & High power consumption \\
\hline Microwave-assisted & $\begin{array}{l}\text { High extraction efficiency } \\
\text { Environmentally friendly and safe } \\
\text { More economical, fast operational time } \\
\text { Efficient on wet biomass } \\
\text { Improved extraction yield }\end{array}$ & $\begin{array}{l}\text { Poor efficiency may occur when target } \\
\text { compounds or the solvents are non-polar, } \\
\text { or volatile } \\
\text { At commercial scale the cost maybe limiting }\end{array}$ \\
\hline Enzymatic disruption & $\begin{array}{l}\text { Minimal damage to the lipid and hydrocarbons, promis- } \\
\text { ing on wet biomass } \\
\text { Safe and environmentally friendly } \\
\text { Easily scalable }\end{array}$ & $\begin{array}{l}\text { Long cycle time } \\
\text { Species dependent }\end{array}$ \\
\hline Supercritical carbon dioxide & $\begin{array}{l}\text { Promising green technology } \\
\text { Lipid extraction rate is fast } \\
\text { Can be used for large-scale } \\
\text { Production of solvent-free extract } \\
\text { Environmentally friendly and safe } \\
\text { Low toxicity solvents }\end{array}$ & High capital cost \\
\hline Solvent extraction & $\begin{array}{l}\text { High efficiency } \\
\text { Simple and economical }\end{array}$ & $\begin{array}{l}\text { Lipid extraction rate is slow } \\
\text { Expensive organic solvent is needed } \\
\text { solvent recovery is energy intensive } \\
\text { Solvents are flammable and/or toxic }\end{array}$ \\
\hline
\end{tabular}

Table 8 Comparison of supercritical- $\mathrm{CO}_{2}$ extraction with solvent extraction. Reproduced from Halim et al. (2012, Sahena et al. (2009)

\begin{tabular}{|c|c|c|}
\hline Solvent extraction & Supercritical $\mathrm{CO}_{2}$ extraction & References \\
\hline $\begin{array}{l}\text { Procedure uses expensive/toxic organic solvents. Therefore, } \\
\text { energy-intensive solvent removal operations are needed }\end{array}$ & $\begin{array}{l}\text { Procedure use non-toxic/inexpensive } \mathrm{CO}_{2} \text { as a solvent. Extra } \\
\text { unit operations are not needed }\end{array}$ & Sahena et al. (2009) \\
\hline $\begin{array}{l}\text { Polar substances get dissolved along with the lipophilic } \\
\text { substances from the raw material due to poor selectivity of } \\
\text { the solvent. During solvent removal operations, these polar } \\
\text { substances form polymers, which lead to discoloration of the } \\
\text { extract }\end{array}$ & $\begin{array}{l}\text { No such possibility exists since } \mathrm{CO}_{2} \text { is highly selective and no } \\
\text { chance of polar substances forming polymers exists }\end{array}$ & Sahena et al. (2009) \\
\hline $\begin{array}{l}\text { When non-polar organic solvents is used, only limited amount } \\
\text { of neutral lipids can be extracted. When non-polar/polar } \\
\text { organic solvent mixture is used, both neutral lipids and polar } \\
\text { lipids are extracted }\end{array}$ & $\begin{array}{l}\text { The polarity of } \mathrm{SC}_{-} \mathrm{CO}_{2} \text { can be varied by employing polar co- } \\
\text { solvents }\end{array}$ & Halim et al. (2012) \\
\hline Requires little energy as ambient conditions are carried out & $\begin{array}{l}\text { Energy intensive due to heating }(\mathrm{T}>\mathrm{TC}) \text { and compression } \\
(\mathrm{P}>\mathrm{PC}) \text { requirement for } \mathrm{CO}_{2} \text { supercritical state }\end{array}$ & Halim et al. (2012) \\
\hline
\end{tabular}

oil can be treated through a dilute citric acid to remove gums, phospholipids, and proteins that become insoluble in oil when hydrated (Kanakraj and Dixit 2016). This process typically utilizes water at $60^{\circ} \mathrm{C}$ and $1 \mathrm{wt} \%$ of oil, separating hydrated phosphatides and other contaminants either by decantation or continuously by centrifugation. The separated aqueous phase and cellular debris can be fed to anaerobic digestion to produce biogas. The process decreases salt formation in the oil by greatly reducing the $\mathrm{Ca}, \mathrm{Cu}, \mathrm{Mg}$, and Fe content, ions, which can accelerate its oxidative degradation and phospholipids such as lecithin that finds widespread food and technical industrial applications (Adekunle et al. 2016).

\section{Chemical processes-transesterification}

The most used direct chemical process in biofuel production is the transesterification of triglycerides of fatty acids into biodiesel (Demire 2018b; Kargbo 2010). The transesterification process has yields of up to $98 \%$ (Umdu et al. 2009). and can be further improved toward cost-effective separation processes of biodiesel from methanol and 
converting glycerol into value-added glycerol carbonate (Nguyen and Demirel 2011a, b; Umdu et al. 2009).

Fischer-Tropsch synthesis is another well-known indirect chemical process for producing biofuel from biosyngas containing mainly $\mathrm{CO}$ and $\mathrm{H}_{2}$ and produced from gasification of a biomass. A representative FischerTropsch $(\mathrm{F}-\mathrm{T})$ reaction is

$$
\begin{gathered}
(2 n+1) \mathrm{H}_{2}+n \mathrm{CO} \rightarrow \mathrm{C}_{n} \mathrm{H}_{2 n+2}+n \mathrm{H}_{2} \mathrm{O} \\
\left.-170 \mathrm{~kJ} / \text { mole (at } 250^{\circ} \mathrm{C} \text { and } 15 \mathrm{~atm}\right)
\end{gathered}
$$

In the production of diesel fuel, " $n$ " can be in the range of 12-25; therefore, an $\mathrm{H}_{2}$ to $\mathrm{CO}$ molar ratio of close to 2 is required. An iron-based catalyst and an operating temperature of $350{ }^{\circ} \mathrm{C}$ will produce mostly gasoline, while a cobalt base and an operating temperature of $200{ }^{\circ} \mathrm{C}$ will produce mostly diesel fuel. The crude bio-oil produced in the $\mathrm{F}-\mathrm{T}$ synthesis is distilled to naphtha, distillate, and wax, which are processed through a series of refining and reforming steps with hydro-treatment and catalytic processes to produce gasoline and diesel at the required configurations.

A hydro-deoxygenation reduces the biodiesel to saturated alkanes and propene at $350{ }^{\circ} \mathrm{C}$ and 35 bar producing green diesel. Alkanes mixture of $\mathrm{C} 15-\mathrm{C} 17$ go through a hydrocracking and hydro-isomerization, in which chain lengths are reduced and branching is introduced. Possible products are jet fuel (54\%), diesel (10\%), naphtha $(27 \%)$, which are separated in an atmospheric distillation column. A propane rich light gas stream also is recovered in the refining. Unused $\mathrm{H}_{2}$ is recycled after cleaning through an amine scrubber (Chen and Xu 2016; Knothe 2010; Nguyen and Demirel 2013).

\section{Biochemical processes}

Algae are advantageous feedstock as they contain carbohydrate, lipids, protein, and other compounds (Demirel 2018a) and can be feedstock for biochemical, and thermochemical processes as seen in Fig. 2. In biochemical conversion of biomass feedstock, various enzymes and microorganisms breakdown and convert organic compounds into alcohols, biogas, biofuel, food/feed, and other chemicals (Demirel 2016). The chemical reactions in biochemical processes undergo at lower temperatures as well as at lower conversion rates compared with the reactions in chemical and thermochemical conversion processes. As a result, biochemical processes are nonpolluting natural processes requiring low energy and materials. However, suitable process control systems are required to maximize the required product and reduce the side reactions. The biochemical processes are well matured and operated at industrial scales: (1) fermentation of sugars in biomass crops to alcohols, primarily to bioethanol and (2) anaerobic digestion of biomass and its wastes to methane known as biogas and residue that can be used as fertilizers. Beside these mainstream processes, there are darkfermentation, photo-fermentation, and others under development.

\section{Thermochemical processes}

Thermochemical conversion processes of combustion, gasification, and pyrolysis take place at high temperatures $\left(450-1200{ }^{\circ} \mathrm{C}\right)$ and are very common for converting various biomass feedstock and wastes into useful fuels and chemicals. In the indirect biomass gasification, heat for the gasification comes from an external source, while a part of biomass is combusted in the direct gasification. In a conventional gasification process, biomass (or other carbon-containing feedstock) reacts with limited oxygen (or air), $\mathrm{CO}_{2}$, and high temperature steam $\left(750-1100{ }^{\circ} \mathrm{C}\right.$ ) to produce synthesis gas (biosyngas). For dry basis, $\mathrm{H}_{2}$ and $\mathrm{CO}$ contents of biosyngas are around $32 \mathrm{vol} \%$ and $29 \mathrm{vol} \%$, respectively. After removing impurities (including nitrogen, methane, carbon dioxide) and enriched to desired ratio of $\mathrm{H}_{2}-\mathrm{CO}$, biosyngas can then be chemically converted into methanol, ethanol and other liquid fuels using the F-T synthesis. The water-gas shift reaction can increase the hydrogen content from $6-6.5 \%$ in the initial biosynthesis gas to $30-50$ vol\%. Purification of the syngas accounts $60-70 \%$ of the total capital cost. In chemical looping steam gasification, an oxygen carrier, mainly a metal oxide, transfers oxygen to a biomass, preventing direct contact between the biomass and air to produce the product gas containing mainly $\mathrm{CO}$ and $\mathrm{H}_{2}$. Thus, the oxygen carrier circulates between the fuel reactor and the air reactor (Demirel 2018b).

Pyrolysis uses fast heating to high temperature under anaerobic conditions to break down biomass into a volatile mixture of hydrocarbons. This mixture of hot gases is condensed into a bio-oil with a rich mixture of hydrocarbons, some of which can be converted into biofuels. The raw bio-oil is an emulsion, rendering it incompatible with conventional petroleum oils and requiring additional upgrading to fuels in the gasoline and diesel range by hydrodeoxygenation if it were to be used as transportation fuel because of poor volatility, high viscosity, coking, corrosiveness, and poor cold-flow properties. Catalytic upgrading reduces the oxygen level of the bio-oil and increases the $\mathrm{H}_{2}$ proportion, leading to the saturated $\mathrm{C}-\mathrm{C}$ bonds that are fully compatible with petroleum infrastructure and use (Demire 2018b).

\section{Hydrothermal liquefaction}

Hydrothermal liquefaction (HTL) shows much promise as a method of converting whole biomass (water content of $80-95 \%$ ) into bio crude, from which clean biodiesel can be produced (Chen and $\mathrm{Xu}$ 2016). Hot compressed water becomes a highly reactive medium as 
water approaches its critical point $\left(374{ }^{\circ} \mathrm{C}, 22.1 \mathrm{MPa}\right)$, the water viscosity decreases, solubility of organic substances increases (changing from hydrophilic to hydrophobic), and dielectric constant decreases from $78 \mathrm{~F} / \mathrm{m}$ at $25{ }^{\circ} \mathrm{C}$ to $14.07 \mathrm{~F} / \mathrm{m}$. The ionic product of water $K_{w}$ increases $>100$ folds; this makes water an excellent medium for solving organic compound as well as for fast and efficient reactions. High levels of free $\mathrm{H}^{+}$and $\mathrm{OH}^{-}$radicals catalyze many acid and base reactions, such as depolymerization, decarboxylation, and repolymerization of lignins, celluloses, lipids, proteins and carbohydrates, transforming them into bio crude (bio-oil), gas, and char.

In reactor temperature of $220-320{ }^{\circ} \mathrm{C}$ with a $\mathrm{Na}_{2} \mathrm{CO}_{3}$ catalyst and a reaction time of 30-min, biofuel yields of 23 wt\% can be achieved with the bio-oil being a mixture of ketones, aldehydes, phenols, alkenes, fatty acids, esters, aromatics, and nitrogen-containing heterocyclic compounds. Acetic acid is the most common component in the aqueous phase. Several algal species have been studied under HTL to assess the influence of biomass composition on biofuel yield with bio-crude yields of 26.2\% and 19.7\% for Oedogonium and Derbesia, respectively (Akhtar and Amin 2011). ]. Nannochloropsis has also been used in HTL systems at $350{ }^{\circ} \mathrm{C}$ for $60 \mathrm{~min}$ with most of the carbon and hydrogen in the biofuel product and hexane and decane showing the highest bio-oil yields (close to $39 \mathrm{wt} \%$ ), though the carbon recovery is found to be better in polar solvent systems such as chloroform; most of the nitrogen appears as ammonia in the aqueous phase (Suali and Sarbatly 2012). Bio-crude yields of 32\% are achievable with Spirulina (Neveux et al. 2014; Vardon et al. 2011).

HTL can produce bio-crude with high energy recovery (80\%) from biomass to fuel (Broch et al. 2014; López Barreiro et al. 2013). Toor et al. (2013) reported a biocrude yield around 34-38\% for Spirulina platensis after HTL at $310{ }^{\circ} \mathrm{C}$ and 115 bar and 34-46\% for Nannochloropsis salina at $350{ }^{\circ} \mathrm{C}$ and 175 bar. Biller and Ross (2011) reported a bio-crude yield of $27 \%$ and $47 \%$ from HTL of Scenedesmus $\left(350{ }^{\circ} \mathrm{C}\right)$ and Chlorella $\left(300{ }^{\circ} \mathrm{C}\right)$, respectively. Roberts et al. (2013) liquefied harvested algae by hydrothermal process at $350{ }^{\circ} \mathrm{C}$ (autogenous pressure $\sim 2000 \mathrm{psig}$ ) using $60 \mathrm{~g} / \mathrm{L}$ with a yield of aqueous co-products $18.4 \%$ of dry weight and of bio-char (solid) $45 \%$ of dry weight. Vardon et al. (2011) converted Spirulina algae, swine manure, and digested sludge under HTL conditions $\left(300{ }^{\circ} \mathrm{C}, 10-12 \mathrm{MPa}\right.$, and 30-min reaction time). Bio-crude yields ranged from 9.4\% (digested sludge) to $32.6 \%$ (Spirulina) with higher heating values (32.0-34.7 MJ/kg). Feedstock composition influenced the individual compounds identified as well as the bio-crude functional group chemistry.
Li et al. (2014) used HTL of a low-lipid high-protein microalgae (Nannochloropsis spp.) and a high-lipid lowprotein microalgae (Chlorella sp.) to investigate the effects of reaction temperature $\left(220-300{ }^{\circ} \mathrm{C}\right)$ with retention time of 30-90 min and total solid of $15-25 \%$ wt of the feedstock. The highest bio-crude yield for Nannochloropsis spp. was $55 \%$ at $260{ }^{\circ} \mathrm{C}, 60 \mathrm{~min}$ and $25 \% \mathrm{wt}$, and for Chlorella sp. was $82.9 \%$ at $220^{\circ} \mathrm{C}, 90 \mathrm{~min}$ and $25 \%$ wt. In particular, the highest hydrocarbons content is $29.8 \%$ and $17.9 \%$ for Nannochloropsis and Chlorella spp., respectively, suggesting that algae composition greatly influences oil yield and quality. Carbon conversion efficiency is $98.3 \%$ under $350{ }^{\circ} \mathrm{C}$ temperature, 60 -min holding time, and $20 \%$ solids for liquefaction of S. platensis. The biocrude obtained under different conditions had 50-63\% light bio-crude fraction (Biller et al. 2012). Marine microalgae Nannochloropsis spp. is converted into a bio-crude and a gaseous product via HTL with a batch holding time of $60 \mathrm{~min}$ at $350{ }^{\circ} \mathrm{C}$ and led to the highest bio-oil yield of $43 \mathrm{wt} \%$. The heating value of the bio-oil is about $39 \mathrm{MJ} /$ $\mathrm{kg}$. Nearly $80 \%$ of the carbon and up to $90 \%$ of the chemical energy of the microalga can be recovered as either bio-oil or gas products (Li et al. 2014). HTL of microalgae Dunaliella tertiolecta cake under various temperatures, holding times, and catalyst dosages are performed by (Shuping et al. 2010). A maximum bio-oil yield of $25.8 \%$ is obtained at $360{ }^{\circ} \mathrm{C}$ and a holding time of $50 \mathrm{~min}$ using $5 \% \mathrm{Na}_{2} \mathrm{CO}_{3}$ as a catalyst. The bio-oil is composed of fatty acids, fatty acid methyl esters, ketones, and aldehydes with an empirical formula of $\mathrm{CH}_{1,44} \mathrm{O}_{0.29} \mathrm{~N}_{0.05}$ and heating value of $30.74 \mathrm{MJ} / \mathrm{kg}$, which can be used as an eco-friendly green biofuel and chemicals (Shuping et al. 2010).

Roberts et al. (2013) use open ponds which were selfinoculated from the wastewater source, resulting in a mixed-culture microalgal community with $29.0 \% \mathrm{dw}$ ash, $48.9 \%$ ash-free dry weight (afdw) carbon, 37.5\% afdw oxygen, and $14.0 \%$ afdw lipid. The harvested algae were processed using $\mathrm{HTL}$ at $350{ }^{\circ} \mathrm{C}$ (autogenous pressures up to $2000 \mathrm{psig}$ ) for $1 \mathrm{~h}$ using $3 \mathrm{~g}$ of freeze-dried algae and $50 \mathrm{~mL}$ of water. The yield of biocrude was 44.5 \pm 4.7 -wt $\%$ afdw, with an elemental weight percent compositions of $78.7 \% \mathrm{C}, 10.1 \% \mathrm{H}, 4.4 \% \mathrm{~N}$, and $5.5 \% \mathrm{O}$, and with an energy content of $39 \mathrm{MJ} / \mathrm{kg}$. HTL also resulted in the formation of $18.4 \pm 4.6 \%$ afdw aqueous co-products and $45.0 \pm 5.9 \% \mathrm{dw}$ solid biochar. The co-products could greatly enhance sustainability and the value chain for algal biofuels, adding markets in carbon sequestration, soil amendments, absorbents, and fertilizers. This demonstration requires further work upon optimizing the energy balance of the conversion method in conjunction with the cultivation strategy and determining the efficacy of the identified co-product markets (Roberts et al. 2013). 
Significant $\mathrm{O}_{2}$ generation from photosynthetic microalgae may reduce the need for high operational cost for mechanical aeration system and to allow bioremediation of organic and inorganic compounds by heterotrophic anaerobic bacteria. Recovered N- and P-rich algal biomass can be used as low-cost fertilizer or as animal feed (Pulz and Gross 2004; Rosenberg et al. 2008).

Conditions should be optimized for producing highquality, low-molecular weight bio-crude from microalgae and cyanobacteria containing low lipid contents, such as Chlorella vulgaris and Spirulina. At 300 to $350{ }^{\circ} \mathrm{C}$ with catalysts of potassium hydroxide, sodium carbonate, acetic acid, and formic acid the yields of bio-crude are higher using an organic acid catalyst and contain $70-75-\mathrm{wt} \% \mathrm{C}$, $10-16-w t \% \mathrm{O}$, and 4-6-wt\% $\mathrm{N}$. The higher heating values (HHV) range from 33.4 to $39.9 \mathrm{MJ} / \mathrm{kg}$. Bio-crude contains aromatic hydrocarbons, nitrogen heterocycles, long chain fatty acids, and alcohols; a large proportion of nitrogen (up to 50-wt\%) is transferred to the aqueous phase in the form of ammonium (Brown et al. 2010).

\section{Algal-based biorefinery}

Besides the production of biofuels, microalgae can be useful for co-production of proteins, carbohydrates, long-chain fatty acids, pigments, all of which become a feedstock for refined products of plastic polymers, pharmaceuticals, cosmetics, food additives, etc. (see Fig. S1 in Additional file 1). Therefore, algae-based biorefinery technology offers the various co-products derived from microalgae in an industrial application, which can be categorized into two groups; energy and non-energy products (Trivedi et al. 2015). Under the combined algal processing concept (Davis et al. 2011), the NREL identified the biorefinery-like opportunity for producing fuel and higher value products from the lipids and the residue biomass using the biochemical and thermochemical conversion processes.

The algal carbohydrates exist in the form of starch, glucose, cellulose and various kinds of polysaccharides that can be converted into various co-products by biological fermentation, or chemical upgrading pathways (see Table S1 in Additional file 1).

Microalgae contain various types of photosynthetic pigments including chlorophylls, carotenoids and phycobiliproteins. Microalgal pigments have pharmaceutical and nutraceutical applications in industry. Some of the applications of pigments derived from microalgae are in Table S2 in Additional file 1. Astaxanthin that can be derived from Haematococus pluvalis has important benefits in the treatment of free radical-associated diseases such as eye disease, cardiovascular diseases, and cancers (Han et al. 2013). Many pigments from microalgae can be used as natural colorants in food, drugs and cosmetic industry. Avoiding toxic effects of artificial colorants enlighten the importance of microalgae pigments as a source of natural colors.

\section{Feedstock for bioproducts}

Third-generation biofuels can be viable alternative energy resource with a successful integration of biofuels sector with the production of high-value bioproducts (Table 9) (Rodolfi et al. 2009) and microalgae propagation techniques with $\mathrm{CO}_{2}$ sequestration and bioremediation of wastewater treatment potential (Bahadar and Bilal Khan 2013; Davis et al. 2016; Muylaert et al. 2015; National Research Council 2012b; Raeesossadati and Ahmadzadeh 2015; Roberts et al. 2013).

Drying and selling of high-protein meal as feed have a potential to increase revenues and decrease the fuel MSP. However, feed markets are local and aspects of nutritional value, toxicity, and customer adoption are some of the central issues (Davis et al. 2011).

\section{Feedstock for anaerobic digestion}

Both, macro- and microalgae are suitable renewable substrates for the anaerobic digestion process to produce $\mathrm{CH}_{4}$ rich biogas as well as fertilizer. The nutrient can be recycled after digestion. Biogas can be used for producing electricity or thermal energy, or may be enriched by capturing $\mathrm{CO}_{2}$ toward drop-in renewable natural gas production. Combustion of biogas allows a reduction in the external power demand up to $\sim 40 \%$ (Shuping et al. 2010). The incorporation and integration of anaerobic digestion with microalgae-based biofuels production can attain higher efficiency and improve sustainability in the production of biofuels from microalgae. There are several technical issues associated with anaerobic digestion of microalgae biomass including the low concentration of biodegradable (digestible) microalgae substrates, cell wall disruption, high lipid concentrations, ammonia inhibition, low $\mathrm{C} / \mathrm{N}$ ratio and co-digestion (Shuping et al. 2010). The resulting digestate is a functional nutrient source for the continued growth of additional microalgal biomass, and helps to close the nutrient loop associated with large-scale microalgae biomass production. With a greater understanding of the different microalgae species and their characteristics, the anaerobic digestion of microalgae and their residues must be optimized to play an essential role in the sustainable future of clean energy derived from microalgae (Shuping et al. 2010).

The process of biogas production from algal biomass is an alternative technology that may have larger potential energy output compared to green diesel, biodiesel, 
Table 9 Some possible co-products of algal biofuel production (Hejazi and Wijffels 2004; Lorenz and Cysewski 2000; Pulz and Gross 2004; Rosenberg et al. 2008; Spoalore et al. 2006)

\begin{tabular}{|c|c|c|c|}
\hline Market & Product & Species & Potential application \\
\hline Hydrogen & Bio-hydrogen & C. reinhardtii & Hydrogenation \\
\hline Chemicals & Biohydrocarbons & Nannochloropsis & Biochemical \\
\hline Fuel/chemicals & Bio-oil & Nannochloropsis & Biofuel, chemicals, biochar \\
\hline Biofuel/product & Alcohols: biomethanol, bioethanol & Spirulina & Biofuel \\
\hline \multirow[t]{4}{*}{ Polyunsaturated fatty acids } & Docasahexanoic acid & Crypthecodinium, Schizochytrium & Nutritional food \\
\hline & Eicosapentanoic acid & Nannochloropsis, Phaeodactylum, Nitzschia, Pavlova & \\
\hline & $\gamma$-Linolenic acid & Spirulina & \\
\hline & Arachidonic acid & Porphyridium & \\
\hline \multirow[t]{2}{*}{ Antioxidants } & Astaxanthin & H. pluvialis & \\
\hline & $\beta$-Carotene & Dunaliella salina & Nutritional food, cosmetics \\
\hline Fluorescent label & Phycoerythrin, phycocyanin & Spirulina & Biomedical Research \\
\hline Recombinant proteins & $\begin{array}{l}\text { Cytokines-interleukin- } 6 \text { interferon } \\
\text { gamma and beta }\end{array}$ & & Pharmaceuticals \\
\hline \multirow[t]{2}{*}{ Nutrition } & Aquaculture feed & Isochrysis, Nannochloropsis, Tetraselmis & Aquaculture \\
\hline & Animal feed & Various & Agriculture \\
\hline \multirow[t]{3}{*}{ Polysaccharides } & Agar & Various & Food products \\
\hline & Alginates & & \\
\hline & Carrageenans & & \\
\hline
\end{tabular}

bioethanol, and hydrogen production processes (Ehimen et al. 2011). Several techno-economic constraints need to be improved before the production of biogas from algal biomass becomes economically feasible. These constraints include a high cost of biomass production, limited biodegradability of algal cells, a slow rate of biological conversion, and high sensitivity of methanogenic microorganisms. The research opportunities include: (i) design of systems for algae cultivation and anaerobic digestion, (ii) optimization of algae cultivation in wastewater, nutrients recycling, and algal concentration, (iii) enhancement of algal biomass digestibility and conversion rate by pretreatment, (iv) integration with other technological processes (e.g., wastewater treatment, codigestion with other substrates, and $\mathrm{CO}_{2}$ sequestration), (v) development and adaptation of molecular biology tools for the improvement of algae and anaerobic microorganisms, and (vi) estimation of the environmental impact, energy and economical balance by performing a life cycle analysis (Muñoz and Guieysse 2006). In addition to revenues from the biodiesel, anaerobic digestion of the leftover biomass can produce biomethane; assuming a methane yield of $0.3 \mathrm{~g} / \mathrm{L}$ for biomass after oil extraction, a methane heating value of $55,500 \mathrm{~kJ} / \mathrm{kg}$, and an electricity generation efficiency of $30 \%, 70.6 \mathrm{GWh} /$ day of cost offsetting electricity can be produced from algae grown in US wastewater treatment plants (Harun et al. 2013).

\section{Life cycle assessment (LCA) of algae-to-energy systems}

The energy return on investment (EROI) is an important measure to determine the energy efficiency of the algae biofuels. Energy ratio greater than unity refers to a positive energy balance and should be achieved. In particular, an EROI is greater than 7 is desired to produce an algal energy product (Chisti 2013). EROI values for algal biofuels are generally lower than unity. Ketzer et al. (2018) summarizes numerous existing studies of EROI for bioenergy production. Figure 3 demonstrates the energy inputs according to production steps. The wide variation of EROI results from 0.14 to 3.35 is found.

Several useful life cycle assessment (LCA) studies are available that assess the energy balance and environmental impacts of large-scale algae-to-energy systems. However, these studies are theoretical because there is no full-scale commercial algae cultivation system in operation and comparing different life cycle analysis with one another is difficult. Table 10 demonstrates the selected different modeling assumptions of microalgaeto-energy LCA that have been published to date. Most of the reviewed LCA studies focus on the energy balance and greenhouse gas (GHG) emissions to determine the sustainability of algae-to-energy production. Quantified aspects of LCA include the following sustainability metrics: (i) material intensity (nonrenewable resources of raw materials, solvents/unit mass of products), (ii) energy intensity (nonrenewable energy/unit mass of products), 


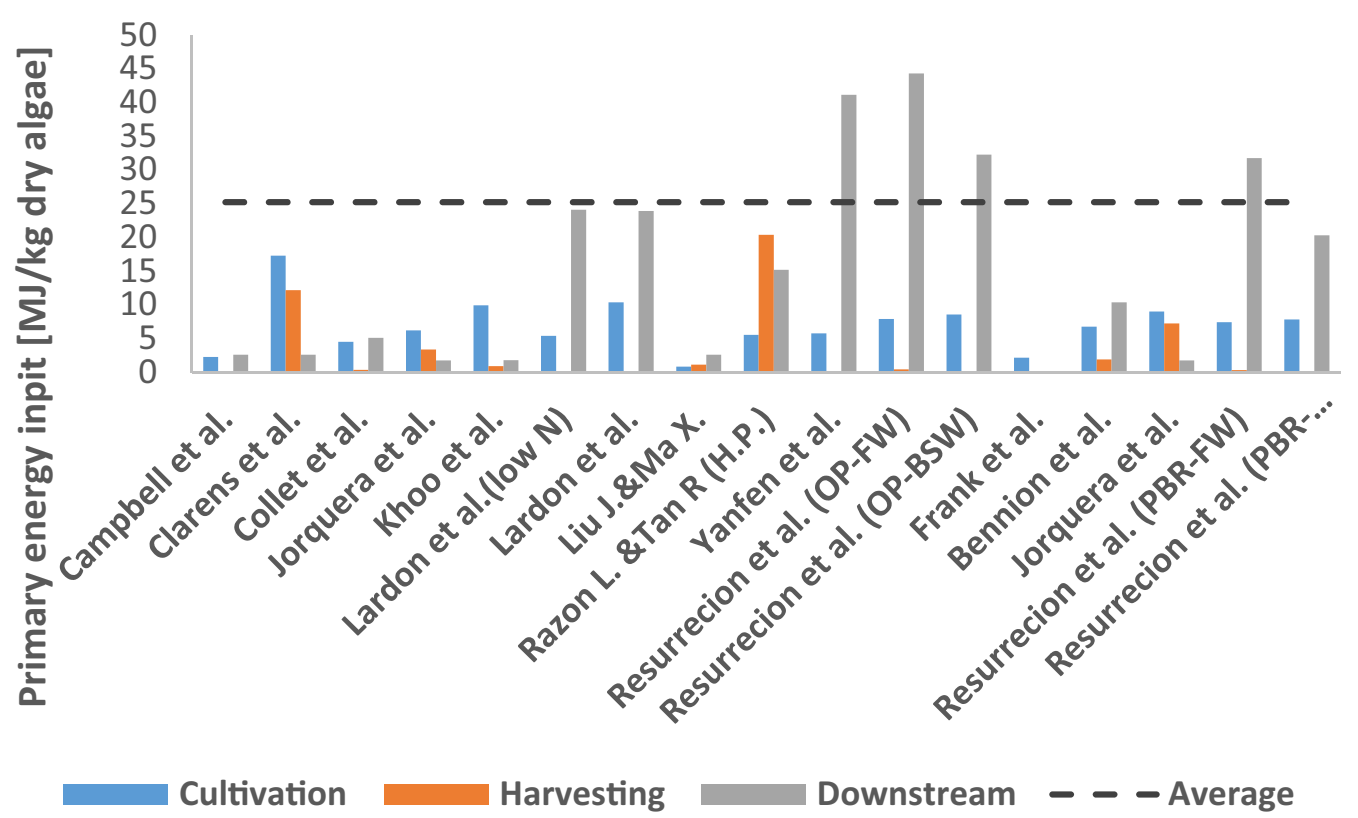

Fig. 3 Energy inputs according to production steps (Ketzer et al. 2018)

Table 10 Selected life cycle modeling assumptions for several studies

\begin{tabular}{|c|c|c|c|c|}
\hline Process & Growth & System boundaries & Functional unit & References \\
\hline $\begin{array}{l}\text { Flocculation, oil extraction, biodiesel } \\
\text { production }\end{array}$ & $\begin{array}{l}\text { Open raceway ponds } \\
\text { Nutrient-sufficient/nitrogen deprived } \\
\text { cultivation }\end{array}$ & Cradle-to-grave & $1 \mathrm{MJ}$ fuel & Bernard (2009) \\
\hline $\begin{array}{l}\text { Flocculation, homogenization and sol- } \\
\text { vent extraction, biodiesel production }\end{array}$ & Open raceway ponds & $\begin{array}{l}\text { Cradle-to-grave } \\
\text { Cradle-to-grave }\end{array}$ & 1 ton biodiesel & Stephenson et al. (2010) \\
\hline $\begin{array}{l}\text { Flocculation and centrifugation, } \\
\text { homogenization and solvent extrac- } \\
\text { tion, biodiesel production }\end{array}$ & Tubular-photo bioreactors & & 1 ton biodiesel & \\
\hline $\begin{array}{l}\text { Filter press/centrifuge and drying, oil } \\
\text { extraction, biodiesel production }\end{array}$ & Photo bioreactors + open ponds & Cradle-to-grave & 1000 MJ fuel & Sander and Murthy (2010) \\
\hline $\begin{array}{l}\text { Centrifuge, drying, oil extraction, bio- } \\
\text { diesel production }\end{array}$ & $\begin{array}{l}\text { Bubble column Photobioreactor } \\
\text { (bcPBR) }\end{array}$ & Cradle-to-grave & $1 \mathrm{~kg}$ dry biomass & Sevigné Itoiz et al. (2012) \\
\hline $\begin{array}{l}\text { Wet extraction: cultivation, extraction, } \\
\text { solvent recovery, oil separation, belt } \\
\text { filter press, feed dryer, and biodiesel } \\
\text { production }\end{array}$ & Open raceway ponds & Cradle-to-grave & $1 \mathrm{MJ}$ fuel & Passell et al. (2013) \\
\hline $\begin{array}{l}\text { Chemical flocculation, mechanical } \\
\text { drying/spray drying, oil extraction, } \\
\text { biodiesel production }\end{array}$ & Open raceway ponds & Cradle-to-grave & 1 kg biodiesel & Togarcheti et al. (2017) \\
\hline
\end{tabular}

(iii) potential environmental impact (pollutants and emissions/unit mass of products), and (iv) potential chemical risk (toxic emissions/unit mass of products). Data for allocation-related questions would be valuable for LCA for systems with complex interdependencies and with multi inputs and outputs, and recycle streams. Stochastic tools such as Monte Carlo analysis can be used for estimating a range of output values from a series of input variables. Minimizing the possible subjective system boundary interpretation of data can similarly be achieved through performing sensitivity analyses to quantify the interdependency between inputs and outputs of individual and combined processes. Beside the economics analysis, sustainability metrics should also be an integral part of the feasibility analysis in a multi-criteria Pugh decision matrix (Matzen et al. 2015). 


\section{Techno-economic analysis (TEA)}

There is a large gap when it comes to utilizing the technology developed in a lab environment and in a full-scale industrial setting. No plants have yet been built at an industrial scale leading to information on the actual costs associated with the large-scale production of algal biofuel. Through the American Recovery and Reinvestment Act of 2009, research, development, and demonstration projects funded by the US DOE and others are targeting to commercialization of algal biofuels. The ability to quickly test and implement new and innovative technologies in an integrated process will be a key component to accelerating progress toward commercialization (Cauchie et al. 2000). TEA requires estimated mass and energy balances from an optimized process based on a capacity and a pathway (see Fig. S2 in Additional file 1) in order to estimate capital and production costs aiding in net present value (NPV) analysis from discounted cash flow diagrams. This procedure is similar to NREL's approach for TEA (Davis et al. 2016). A simulation package can be used to prepare an optimized process based on the minimum selling price (MSP) of a primary product (Nguyen and Demirel 2011a, b).

Estimated cost of lipid production to achieve a $10 \%$ return is around to be $\$ 8.52 /$ gallon for open ponds and $\$ 18.10 /$ gallon for PBRs in 2011 US dollars (Davis et al. 2011). The near-term research should focus on maximizing lipid content as it offers more substantial cost reduction potential relative to an improved algae growth rate. These results reiterate that the economics of microalgal biofuel production would not be currently feasible. However, there is room for significant cost reduction potential through both biological, chemical, and technological improvement opportunities; near-term research should focus on maximizing lipid content with algal growth rates, sustainable nutrient and water supply, and capital cost reductions through low-cost equipment and optimizing the supply of nutrient and $\mathrm{CO}_{2}$. Economics are influenced strongly by feedstock costs and seasonality (Davis et al. 2011). From a sustainability standpoint, it is important to consider carbon, nutrient, and water balances, recycle opportunities, and delivery sources. Algal biofuel economics could be further improved in the near term through utilizing the spent algal biomass for more valuable co-products beyond biogas for power thermal energy generations (Davis et al. 2011).

Annual operating costs for algal-based biofuel production are dominated by biomass and facility costs, which include depreciation, maintenance, insurance, and facility overhead. Biomass cost is mostly associated with water cost if it is assumed that $90 \%$ of the nutrients can be recycled after anaerobic digestion and $\mathrm{CO}_{2}$ is assumed to be freely available (Davis et al. 2011). Energy analysis of the overall process has shown that energy requirements for cultivation and drying of biomass are two of the most energy-intensive parts, with some estimates putting the whole process in an energy deficit (Davis et al. 2011). This shows the need for wet extraction and transesterification processes to reduce costs, energy usage, and improve environmental impact (Pienkos and Darzins 2009; Roberts et al. 2013; Valdez et al. 2011). NREL (Davis et al. 2016) NREL performed a feasibility-level analysis for a conversion pathway with a cost target of below $\$ 5 / \mathrm{gal}$ lon gasoline equivalent (gge) in 2011 US\$ (ultimate target: \$3/gge). An average of 1339 afdw ton biomass/day in a facility and an overall fuel selling price of $\$ 4.35 /$ gge in 2011 US\$-dollars is associated with a net fuel yield of 141 gge/dry ton. These values are attributed to a high (41\%) lipid, with high cultivation productivity rates during biomass growth. Based on lower (27\%) lipid, a higher costs at $\$ 5.04 /$ gge is associated with a lower overall fuel yield of 116 gge/dry ton. A realistic possible operation case may fall between these two points for algal growth rate and lipid content. Another simulation of algal growth for the production of biofuel, using raceway cultivation, $\mathrm{CO}_{2}$ sequestered from another source, and added urea as nutrients is performed by (Silva et al. 2014) with the goal of achieving a baseline minimum cost per gallon of algal biodiesel. They have used glycerolysis to reduce the free fatty acid concentration and maximize the biodiesel production and estimated a cost of $\$ 4.34 /$ gallon.

\section{Sensitivity analysis}

Especially, the accumulated effects of the parameters for cultivation, harvesting, extraction may be useful for cost assessment (Davis et al. 2011). As the cost of harvesting decreases, the cost of cultivation becomes significant; if harvesting cost is zero, the cost of cultivation represents $\sim 70 \%$ of the capital cost and the MSP would be around $\$ 500 / \mathrm{bbl}$. The effect of algae productivity $\left(\mathrm{g} / \mathrm{m}^{2}\right.$ day) impacts the area needed to grow the biomass and in turn affects the cost of cultivation (Davis et al. 2011; Klein-Marcuschamer et al. 2013; Silva et al. 2014). The range of the accumulated effects of the low- and highcost scenarios may be wide because of large uncertainties in many parameters (Davis et al. 2011). The curve for MSP versus productivity saturates above $30-35 \mathrm{~g} / \mathrm{m}^{2}$ day, which points the need to improve this parameter simultaneously with other parameters. Sensitivity to nutrient cycle and $\mathrm{CO}_{2}$ cost show that their effects are not as significant as for harvesting and biomass growth. Any efficient lipid recovery process at industrial scale would have a positive impact on economics (Olkiewicz et al. 2015; Silva et al. 2014). The use of fossil fuels in biofuel production process, construction of algal growth facilities, supply of nutrients for algal growth, harvesting of algae, and 
biomass production may lead to a net negative energy output; however, freely available nutrients from the use of wastewater resources may enhance the economy and sustainability of algal biofuel production (Hoffmann 1998; Roberts et al. 2013).

\section{BioBreak model}

One method for estimating the economic viability of biofuels is the biofuel breakeven model or bioBreak. BioBreak model separates the cost of biofuel production into two parts: (1) the willingness to accept (WTA) that is the price that a producer is willing to accept for a dry ton of biomass delivered to a biorefinery, and (2) the willingness to pay (WTP) that is the price a biorefinery would be willing to pay for a dry ton of biomass delivered to the refinery gate. While conceived for the purpose of estimating the economic viability of ethanol production using cellulosic biomaterial, the model can also be used for third-generation biofuels (National Research Council 2012a). The WTA model is based on the cost of establishment and seeding $\left(\mathrm{C}_{\mathrm{ES}}\right)$, the land and biomass opportunity cost $\left(C_{\mathrm{Opp}}\right)$, the cost of harvesting and maintenance $\left(C_{\mathrm{HM}}\right)$, any stumpage fees $(\mathrm{SF})$, the cost of nutrient replacement $\left(C_{\mathrm{NR}}\right)$, the cost of biomass storage $\left(C_{\mathrm{S}}\right)$, transport costs $(D F C, D V C$ and $D)$, the biomass yield per acre $\left(Y_{\mathrm{B}}\right)$, and any government incentives received $(G)$, yielding the final equation

$$
\begin{aligned}
\mathrm{WTA}= & \left\{\left(C_{\mathrm{ES}}+C_{\mathrm{Opp}}\right) / Y_{\mathrm{B}}+C_{\mathrm{HM}}+\mathrm{SF}\right. \\
& \left.+C_{\mathrm{NR}}+C_{\mathrm{S}}+\mathrm{DFC}+\mathrm{DVC} \times D\right\}-\mathrm{G}
\end{aligned}
$$

The WTP model is based on the price of gasoline $\left(P_{\text {gas }}\right)$, the energy equivalent factor $\left(E_{\mathrm{v}}\right)$, octane benefits $\left(V_{\mathrm{O}}\right)$, coproduct value $\left(V_{\mathrm{CP}}\right)$, conversion ratio $\left(Y_{\mathrm{E}}\right)$, nonfeedstock investment costs $\left(C_{\mathrm{I}}\right)$, operating costs $\left(C_{\mathrm{O}}\right)$, and any incentives and tax credits $(T)$ yielding the equation

$$
\mathrm{WTP}=\left\{P_{\text {gas }} \times E_{\mathrm{V}}+T+V_{\mathrm{CP}}+V_{\mathrm{O}}-C_{\mathrm{I}}-C_{\mathrm{O}}\right\} Y_{\mathrm{E}}
$$

The difference between WTA and WTP is the price gap (WTA - WTP), which should be zero or negative for the production of a biofuel process to be economically feasible (Energy Department 2010; National Research Council 2012b).

The equation for cellulosic material is based on land use, resulting in the $\left(C_{\mathrm{ES}}+C_{\mathrm{OPp}}\right) / \mathrm{Y}_{\mathrm{B}}$ term. Altering this section into a single variable that encompasses the costs of establishing a cultivation process provides a more effective look at what plays into the production of algal biomass $\left(C_{\text {rea }}\right)$. The WTA equation can also be modified by dropping the SF as it only applies to tree-based feedstocks and is zero for algal biomass. Transportation costs are also assumed to be minimized in an optimal setting, since cultivation and processing could be collocated resulting in the simplified equation below

$$
\mathrm{WTA}_{\text {algae }}=\left\{C_{\mathrm{Rea}}+C_{\mathrm{HM}}+C_{\mathrm{NR}}+C_{\mathrm{S}}\right\}
$$

In the WTP, incentives and tax credits are removed dropping the tax credit $\mathrm{T}$ from Eq. (3). Algal biomass is converted into biodiesel, which is not a gasoline additive, so the $P_{\text {gas }}$ should be replaced with the price of diesel $P_{\mathrm{d}}$. Subsequently, there is no need to compare the products of algal biofuel production as biodiesel has nearly the same energy density and octane rating when compared to petroleum-based diesel fuel. This means the $E_{\mathrm{V}}$ value can be taken as one and dropped from Eq. (3), and the $V_{\mathrm{O}}$ is zero, yielding the following simplified equation

$$
\mathrm{WTP}_{\text {algae }}=\left\{P_{\mathrm{d}}+V_{\mathrm{CP}}-C_{\mathrm{I}}-C_{\mathrm{O}}\right\} \times Y_{\mathrm{E}}
$$

Table S3 in Additional file 1 shows the parameters used in estimation of the $\mathrm{WTA}_{\text {algae }}$ based on averages of several ten acre cases assuming a 10 year payoff. All monetary values are for 2011 US\$.

WTP $_{\text {algae }}$ parameters shown in Table S4 in Additional file 1 are obtained through analysis of the WTI Crude Oil Index cross referenced with the US EIA's historic diesel prices. Capital and operating costs are obtained from economic assessments of biodiesel production.

Substitution of the values of parameters from Table S4 in Additional file 1 in Eq. (4) for the $\mathrm{WTA}_{\text {algae }}$ results a value of $\$ 491 /$ ton of biomass in 2011 US\$. Estimated $\mathrm{WTP}_{\text {algae }}$ even at peak crude oil prices of $\$ 150 / \mathrm{Bbl}$ is $\$ 332 /$ ton of biomass in 2011 US\$ after using the values of parameters in Table S4 in Additional file 1 in Eq. (5). Combining these values of WTA and WTP yields a price gap (WTA - WTP) of $\$ 159 /$ ton emphasizing the difference between the cost of biomass and value of making biodiesel from algae at current and even historically high crude values. The price gap should be much lower for an algal-based technology. The price gap indicates the need for increased public sector role to reduce the risk and encourage private investment in algal based fuels and chemicals (Belson Neil 2016). Still, the world-wide efforts toward commercialization of algal fuels are strong and the US leads the commercialization with around $65 \%$ of the startup companies (Bahadar and Bilal Khan 2013).

Direct combustion of algal biomass may be a more viable energy source than biofuel production, especially when the lipid content of dry biomass $(10 \%$ in this field experiment) is lower than the high values reported in labscale reactors (50-60\%) (Sturm and Lamer 2011).

\section{Minimum selling price for algal biomass}

The value of $\mathrm{WTP}_{\text {algae }}$ may also be given by (Chisti 2007) 


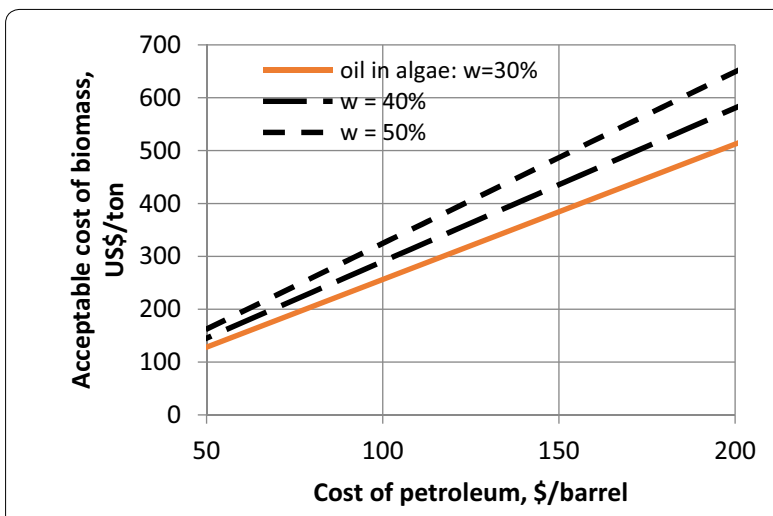

Fig. 4 Acceptable cost of algae biomass with respect to the cost of petroleum

$$
\mathrm{WTP}_{\text {Algae }}=\frac{C_{\text {petroleum }}}{E_{\text {petroleum }}}\left(Q(1-w) E_{\text {biogas }}+Y w E_{\text {biodiesel }}\right),
$$

where $C_{\text {petroleum }}$ is the cost of petroleum, $M_{\mathrm{AB}}$ is the quantity of algae which is energy equivalent to a barrel of crude petroleum, $E_{\text {petroleum }}$ is the energy of a barrel of petroleum, $Q$ is the biogas volume produced by anaerobic digestion, $E_{\text {biogas }}$ is the energy of the biomass, $Y$ is the biodiesel yield, $E_{\text {biodiesel }}$ represents the energy content of biodiesel, and $w$ is the algal biomass oil content. By plugging known values in for all terms, except the cost of petroleum and graphing the Cost of Biomass over the cost of petroleum, the acceptable cost of biomass can be calculated. Figure 4 shows the acceptable algal biomass cost versus cost of petroleum at 30,40 and $50 \%$ oil contents of algal biomass. The values for $\mathrm{WTP}_{\text {algae }}$ increase with the higher oil content of algal biomass delivered and decrease for lower petroleum costs. At \$150/barrel of petroleum, the value of $\mathrm{WTP}_{\text {algae }}$ changes between $\$ 380$ / ton and $\$ 490 /$ ton as the oil content increases from 30 to $50 \%$. These are in line with the costs obtained from the biobreak model and show that at higher oil yields of algal biomass, the price gap becomes narrow.

A predicted petroleum cost of over $\$ 150 /$ barrel would be required to narrow the price gap (Chisti 2008, 2013).

No economic assessment of algal biofuels has shown a positive return on investment within a reasonable timeframe (Bahadar and Bilal Khan 2013). EROI values calculated from several different LCA studies according to the production systems are shown in Figs. S3 and S4 in Additional file 1 (Ketzer et al. 2018). An average EROI of 0.3 for closed PBRs increases to an average of 0.99 for open-pond systems.

While not currently feasible, there are notable areas where improvements in technology could be made, such as increasing lipid contents and growth rates by selecting the best strains for the nutrients available and maximizing growth conditions. Both biological and engineering opportunities exist to reduce costs and increase production. Better cultivation, by maximizing lipid contents, and decreased extraction costs are areas with the most potential for profit improvements (Raeesossadati and Ahmadzadeh 2015; Silva et al. 2014). The research opportunities include: (1) optimum design of systems for algae cultivation and anaerobic digestion, (2) optimization of algae cultivation in wastewater, nutrients recycling and algal concentration, (3) enhancement of algal biomass digestibility and conversion rate by pretreatment, (4) deep integration with other technological processes (e.g., wastewater treatment, co-digestion with other substrates, carbon dioxide sequestration), (5) development and adaptation of molecular biology tools for the improvement of algae and anaerobic microorganisms, (6) application of information technologies, and (7) estimation of the environmental impact, energy and economical balance by performing a life cycle analysis (Bohutskyi and Bouwer 2013).

\section{Optimum capacity}

Besides, land use and water use must be considered in algae cultivation (Matzen and Demirel 2016). Davis et al. (2011) used TEA to model for the production of algal biomass in open ponds to understand the impact of scale on the economics. This study determined that production costs would be significantly lower when a cultivation facility uses around 5000 acres of open ponds producing around $\$ 1000 /$ dry ton biomass. This shows that economies of scale would not play a significant role in reducing the production cost at larger plant scales.

\section{Food energy and water nexus}

By 2050, the demand for energy will nearly double globally, with water and food demand estimated to increase by over $50 \%$. The ability of existing food-energy-water (FEW) systems to meet this growing demand is constrained by the competing needs for limited resources and by climate change impacts. The interlinkage (see Fig. S5 in Additional file 1) between the FEW supply systems is a major consideration in countries with sustainable development strategies (Ferroukhi et al. 2015) and forcing the exploration of the feasibility of MW recycling and resource recovery, such as the nutrients of $\mathrm{N}$ and $\mathrm{P}$ as well as water. The complex interconnections show that: (i) water supply is influenced by demands from energy and food sectors, (ii) food production depends both on water and energy, and (iii) energy production and operations require water (see Fig. S5 in Additional file 1) (Ferroukhi 
et al. 2015). Climate change, particularly drought, affects the FEW system balance. Understanding the connections fully can change day-to-day practices of farmers, engineers, resource managers, and policy-makers, and create cutting edge research and strategies for resilience against climate variability and global warming for a more sustainable future. Biology and ecology of large-scale algal cultures and engineering of algal biomass down processing are essential for a sustainable FEW system.

\section{Discussions and conclusions}

More than half (52\%) of the total lignocellulosic biomassbased advanced biofuels projects failed by 2015. Policies behind the biofuel drive are: Clean Air Act 1970, Energy Policy Act of 2005, Advanced Energy Initiative 2006, RFS, California Low Carbon Fuel Standard 2016, and Food, Conservation, and Energy Act 2008.

A long list of 23 external and internal barriers causing this are easily identified. Industry stakeholders include the advisory board ( $A B)$ industry members, government representatives, and others (publishers, journalists, suppliers, etc.). Main internal barriers are product development, byproduct and coproduct distribution and marketing, continuous project growth, management, strategy, technology for conversion rate and yield. Main external barriers are competition, funding, supplies, DOE and EPA pathway processes, USDA pathway processes Tax credits, RFS, Waiver credits, renewable volume obligation, Renewable identification numbers, energy costs, and third part relationships. Technology issues are the most important internal barrier and funding (debt management) and renewable fuel standards (RFS) are the most important internal barriers.

RFS requires that transportation fuels contain at least $10 \%$ biofuel. However, shortage of biofuel and abundant supply of fossil fuels lead to subsidies for these objectives: (1) Sequester carbon reduce GHG emissions, (2) Achieve greater energy efficiency, (3) Integrate rural programs into increasing energy security, (4) Stimulate economic growth and development, (5) Obtain feasible conversion technologies. Despite the subsidies and demand for biofuel, AB technology did not become feasible (Withers et al. 2017).

Prospective schemes for the scale-up of algal production need to be elaborated by careful process modeling, simulation, and optimization with LCA from the design stage. Without careful assessment of the mass and energy balances, and ecological impacts, there is a danger that many proposed schemes may end up as unsustainable. The data from real-life demonstration or pilot plant at a realistic scale under prevailing weather conditions help to assess possible productivities in practice. Selecting high-lipid-producing strains optimized to regional climate conditions and to the large-scale production of algae biomass, and preferably also amenable to metabolic engineering, will be crucially important.

Integration of engineering and biology is essential, since neither of alone is likely to yield an appropriate solution. For example, a change in algal lipid composition under stress conditions is often observed, which means that the oil cannot be used directly for biodiesel production. However, it has been reported that the freshwater green microalga Parietochloris incisa enhances not only its TAG production under $\mathrm{N}$ starvation but also the proportion of arachidonic acid, a valuable nutraceutical, in TAGs. In this case, the valuable by-product could make biodiesel production from this species viable. Thus, establishing the feasibility of algal biofuel production regardless of energy input will be an important step in providing the platform for optimization, and also for establishing promising lines for future research. This is essentially what has happened with first-generation biofuel where, despite the concerns over food prices, land use and so on, it has led to the development of infrastructure, policies, and know-how (Scott et al. 2010).

Microalgae can contribute a significant portion of the renewable fuels that will be required by the Renewable Fuels Standard described in the 2007 Energy Independence and Security Act of the United States (National Research Council 2012a). Many different paths are possible to produce biofuel out of algal biomass. Continued research into strain or community of strain selection to maximize lipid content should continue, with emphasis on strains already noted for their high lipid content and growth rates, such as Nannochloropsis, Phaeodactylum, and Chlorella. Cultivation of algal biomass in both raceway ponds and PBRs comes with advantages and disadvantages, which are often not compatible with the next down process of harvesting. PBRs show promise for minimizing resource waste and maximizing lipid content, but their increased cost makes them even more prohibitive than raceway ponds. On the other hand, raceway ponds end up with dilute biomass, which makes the harvesting very expensive. This clearly indicates that the individual and the whole processes have their own dynamics, constraints, and optimums hence, it is crucial to synchronize the down processing successfully for a sustainable algalbased biofuel/bioproduct sector.

While several methods for extraction and processing are available, some are more promising than others are. The economics and sustainability of a viable algalbased fuel and chemical platform will depend upon a close integration of cultivation and conversion. Hydrothermal liquefaction has shown to be a very promising possibility for such integration. With a low energy and chemical requirements as well as few processing steps, 
hydrothermal liquefaction could lead the way in biodiesel extraction methods. This form of extraction and processing could also allow coproducts to boost the potential profits from algal biomass.

Algae could prove to be the biomass feedstock of the future beside the sugar. A spike in petroleum costs could cause algae to become economically feasible sooner rather than later. Continuing research and development are valuable due to the potential gains that can be made from both an energy production and an environmental protection standpoint. The ability of algae to build a sustainable food-energy-water nexus, by treating wastewater, while simultaneously producing renewable energy and high-value chemicals, without interfering with the food supply chain is a promising aspect that could play into decision to commercialize algal-based biorefinery in the near future. An attempt to get a working industrial scale plant, even with the notable economic infeasibility could also prove extremely valuable, as more information could be gained by such a venture, than is currently available and would not be obtained through research pathways. The research opportunities include: (1) optimum design of systems for algae cultivation and anaerobic digestion, (2) optimization of algae cultivation in wastewater, nutrients recycling and algal concentration, (3) enhancement of algal biomass digestibility and conversion rate by pretreatment, (4) deep integration with other technological processes (e.g., wastewater treatment, codigestion with other substrates, carbon dioxide sequestration), (5) development and adaptation of molecular biology tools for the improvement of algae and anaerobic microorganisms, (6) application of information technologies, and (7) estimation of the environmental impact, energy and economical balance by performing a life cycle analysis (Bohutskyi and Bouwer 2013).

A large scale of sustainable algal-based biofuels and bioproducts system needs careful integration of biology, ecology, and engineering. This will ensure that careful assessment of the energy balances and ecological constraints are exercised despite the lack of real-economic data from a large-scale operation under prevailing ecological constraints. Also requisite is the development of high-lipid-producing strains optimized with metabolic engineering under regional ecological conditions. However, integration of biology, ecology and engineering requires an effective collective effort of real-field experimentation that creates considerable challenges. For example, with metabolic engineering and nutrient starvation, quality and yield of lipid as well as high-value chemicals may be adjusted to have a positive impact of feasibility, regardless of energy input.

\section{Additional file}

Additional file 1. Additional materials.

\section{Abbreviations}

ASP: aquatic species program; MW: municipal wastewater; NUE: nutrient use efficiency; PBR: photo bioreactor; HHV: higher heating value; NPV: net present value; WTA: willingness to accept; WTP: willingness to pay; USDA: US department of agriculture; FEW: food-energy-water; TAG: triacylglycerol; $C_{\mathrm{HM}}$ : harvesting and maintenance cost; $C_{\mathrm{NR}}$ : cost of nutrient replacement; $Y_{\mathrm{B}}$ : biomass yield; $P_{\text {gas }}$ : price of gasoline; $P d$ : price of diesel; Co: operating cost; Vo: octane benefits; FW: fresh water; TEA: techno-economic analysis; LCA: life cycle assessment; EROI: energy return on investment; GHG: greenhouse gas; ORP: open raceway pond; MSP: minimum selling price; RFS: renewable fuel standards; DOE: US department of energy; EPA: US environmental production agency; TGA: triglyceride acid; $C_{E S}$ : cost of establishment; $C_{O P p}$ : land and biomass opportunity cost; $C_{5}$ : cost of biomass storage; $S F$ : stumpage fees; $C_{i}$ : nonfeedstock investment cost; $V_{\mathrm{cp}}$ : coproduct value; $Y_{\mathrm{E}}$ : conversion ratio; $\mathrm{Ev}$ : energy equivalent factor; BSW: brackish-to-saline water.

\section{Authors' contributions}

JA contributed in the processes such as biological systems, algal cultivation, and algal strains. SU: literature search on economics, preparation of some of the tables and figures, and preparing Additional file. YD: engineering analysis, ecological systems, chemical processes, and economic analysis, preparation of some of the tables and figures. PB: biological systems, algal cultivation and harvesting, and biochemical systems. WR: biological systems, algal strains, and biochemical systems. All authors read and approved the final manuscript.

\section{Author details}

${ }^{1}$ Department of Chemical and Biomolecular Engineering, University of Nebraska Lincoln, 207 Othmer Hall, Lincoln 68588-0643, Nebraska, USA.

2 Biochemistry, University of Nebraska Lincoln, N200 Beadle Center, Lincoln, NE 68588-0664, USA. ${ }^{3}$ School of Biological Sciences, University of Nebraska Lincoln, E141 Beadle Center, Lincoln, NE 68588, USA.

\section{Acknowledgements}

The authors thank to Nebraska Center of Energy Research University of Nebraska Lincoln for supporting this Research: 26-1217-0020-106.

\section{Competing interests}

The authors declare that they have no competing interests.

Availability of data and materials

Not applicable.

Consent for publication

Not applicable.

Ethics approval and consent to participate

Not applicable.

Funding

Not applicable.

\section{Publisher's Note}

Springer Nature remains neutral with regard to jurisdictional claims in published maps and institutional affiliations.

Received: 29 August 2018 Accepted: 9 November 2018

Published online: 30 November 2018

\author{
References \\ Adekunle AS, Oyekunle JAO, Obisesan OR, Ojo OS, Ojo OS (2016) Effects \\ of degumming on biodiesel properties of some non-conventional
}


seedoils. Energy Reports 2:188-193. https://doi.org/10.1016/j. egyr.2016.07.001

Akhtar J, Amin NAS (2011) A review on process conditions for optimum bio-oil yield in hydrothermal liquefaction of biomass. Renew Sustain Energy Rev 15:1615-1624. https://doi.org/10.1016/j.rser.2010.11.054

Allnutt FCT, Kessler BA (2015) Biomass and biofuels from microalgae. Algae 2:289-310. https://doi.org/10.1007/978-3-319-16640-7

Aslan S, Kapdan IK (2006) Batch kinetics of nitrogen and phosphorus removal from synthetic wastewater by algae. Ecol Eng 28(1):64-70

Bahadar A, Bilal Khan M (2013) Progress in energy from microalgae: a review. Renew Sustain Energy Rev 27:128-148. https://doi.org/10.1016/j. rser.2013.06.029

Bai X, Ghasemi Naghdi F, Ye L, Lant P, Pratt S (2014) Enhanced lipid extraction from algae using free nitrous acid pretreatment. Bioresour Technol 159:36-40. https://doi.org/10.1016/j.biortech.2014.01.133

Balasubramanian S, Allen JD, Kanitkar A, Boldor D (2011) Oil extraction from Scenedesmus obliquus using a continuous microwave system - design, optimization, and quality characterization. Bioresour Technol 102:33963403. https://doi.org/10.1016/j.biortech.2010.09.119

Bartley ML, Boeing WJ, Daniel D, Dungan BN, Schaub T (2016) Optimization of environmental parameters for Nannochloropsis salina growth and lipid content using the response surface method and invading organisms. J Appl Phycol 28:15-24. https://doi.org/10.1007/s10811-015-0567-8

Belay A (1997) n.d. Mass Culture of Spirulina Outdoors: The Earthrise Farms Experience". In: Vonshak A (ed) Spirulina platensis (Arthrospira), physiology, cell biology and biotechnology. Taylor \& Francis, London, pp $131-158$

Belson NA (2016) Derisking: a strategy for growing the biobased economy [WWW Document]. https://www.biofuelsdigest.com/bdige st/2016/10/24/derisking-a-strategy-for-growing-the-biobased-econo my/

Bendicho C, De La Calle I, Pena F, Costas M, Cabaleiro N, Lavilla I (2012) Ultrasound-assisted pretreatment of solid samples in the context of green analytical chemistry. TrAC 31:50-60. https://doi.org/10.1016/j. trac.2011.06.018

Bennion EP, Ginosar DM, Moses J, Agblevor F, Quinn JC (2015) Lifecycle assessment of microalgae to biofuel: comparison of thermochemical processing pathways. Appl Energy 154:1062-1071

Bernard O (2009) Policy analysis life-cycle assessment of biodiesel production from microalgae. Environ Sci Technol 43:6475-6481. https://doi. org/10.1021/es900705j

Beuckels A, Depraetere O, Vandamme D, Foubert I, Smolders E, Muylaert K (2013) Influence of organic matter on flocculation of Chlorella vulgaris by calcium phosphate precipitation. Biomass Bioenerg 54:107-114. https://doi.org/10.1016/j.biombioe.2013.03.027

Bhatnagar A, Bhatnagar M, Chinnasamy S, Das KC (2010) Chlorella minutissima - a promising fuel alga for cultivation in municipal wastewaters. Appl Biochem Biotechnol 161:523-536. https://doi.org/10.1007/s1201 $0-009-8771-0$

Biller P, Ross AB (2011) Potential yields and properties of oil from the hydrothermal liquefaction of microalgae with different biochemical content. Bioresour Technol 102:215-225. https://doi.org/10.1016/j.biort ech.2010.06.028

Biller P, Ross AB, Skill SC, Lea-Langton A, Balasundaram B, Hall C, Riley R, Llewellyn CA (2012) Nutrient recycling of aqueous phase for microalgae cultivation from the hydrothermal liquefaction process. Algal Res 1:70-76. https://doi.org/10.1016/j.algal.2012.02.002

Blais C, Fournier R, Marsot P (1984) Continuous microalgal culture using swine manure dialysate as a nutrient source. Aquac Eng 3:275-287. https:// doi.org/10.1016/0144-8609(84)90008-6

Bohutskyi P, Bouwer E (2013) Biogas production from algae and cyanobacteria through anaerobic digestion: a review, analysis, and research needs. In: Lee JW (ed) Advanced biofuels and bioproducts. Springer, New York, pp 873-975

Brennan L, Owende P (2010) Biofuels from microalgae - a review of technologies for production, processing, and extractions of biofuels and co-products. Renew Sustain Energy Rev 14:557-577. https://doi. org/10.1016/.rser.2009.10.009

Broch A, Jena U, Hoekman SK, Langford J (2014) Analysis of solid and aqueous phase products from hydrothermal carbonization of whole and lipidextracted algae. Energies 7:62-79. https://doi.org/10.3390/en7010062
Brown TM, Duan P, Savage PE (2010) Hydrothermal liquefaction and gasification of Nannochloropsis sp. Energy Fuels 24:3639-3646. https://doi. org/10.1021/ef100203u

Cai T, Park SY, Li Y (2013) Nutrient recovery from wastewater streams by microalgae: status and prospects. Renew Sustain Energy Rev 19:360-369. https://doi.org/10.1016/j.rser.2012.11.030

Campbell PK, Beer T, Batten D (2011) Life cycle assessment of biodiesel production from microalgae in ponds. Bioresour Technol 102:50-56. https ://doi.org/10.1016/j.biortech.2010.06.048

Cauchie HM, Hoffmann L, Thome JP (2000) Metazooplankton dynamics and secondary production of Daphnia magna (Crustacea) in an aerated waste stabilization pond. J Plankton Res 22:2263-2287. https://doi. org/10.1093/plankt/22.12.2263

Chen J, Xu Q (2016) Hydrodeoxygenation of biodiesel-related fatty acid methyl esters to diesel-range alkanes over zeolite-supported ruthenium catalysts. Catal Sci Technol 6:7239-7251. https://doi.org/10.1039/c6cy0 $1242 f$

Chisti Y (2007) Biodiesel from microalgae. Biotechnol Adv 25:294-306. https:// doi.org/10.1016/j.biotechadv.2007.02.001

Chisti Y (2008) Biodiesel from microalgae beats bioethanol. Trends Biotechnol 26:126-131. https://doi.org/10.1016/j.tibtech.2007.12.002

Chisti Y (2013) Constraints to commercialization of algal fuels. J Biotechnol 167:201-214. https://doi.org/10.1016/j.jbiotec.2013.07.020

Christenson L, Sims R (2011) Production and harvesting of microalgae for wastewater treatment, biofuels, and bioproducts. Biotechnol Adv 29:686-702. https://doi.org/10.1016/j.biotechadv.2011.05.015

Clarens F, Ressureccion EP, White M, Colosi LM (2009) Environmental life cycle comparison of algae $t$ other bioenergy feedstocks. Environ Sci Technol 44:1813-1819. https://doi.org/10.1021/es902838n

Collet P, Hélias Arnaud A, Lardon L, Ras M, Goy RA, Steyer JP (2011) Lifecycle assessment of microalgae culture coupled to biogas production. Bioresour Technol 102:207-214. https://doi.org/10.1016/j.biort ech.2010.06.154

US Congress (2007) Energy independence and security act of 2007. Public Law 1-311. https://doi.org/papers2://publication/ uuid/364DB882-E966-450B-959F-AEAD6E702F42

Davis R, Aden A, Pienkos PT (2011) Techno-economic analysis of autotrophic microalgae for fuel production. Appl Energy 88:3524-3531. https://doi. org/10.1016/j.apenergy.2011.04.018

Davis R, Fishman D, Frank ED, Wigmosta MS, Aden A, Coleman AM, Pienkos PT, Skaggs RJ, Venteris ER, Wang MQ (2012) Renewable diesel from algal lipids: an integrated baseline for cost, emissions, and resource potential from a harmonized model. National Renewable Energy Lab, Golden. https://doi.org/10.2172/1044475

Davis R, Kinchin C, Markham J, Tan E, Laurens L, Sexton D, Knorr D, Schoen P. Lukas J (2014) Process design and economics for the conversion. of algal biomass to biofuels: algal biomass fractionation to lipid- and carbohydrate-derived fuel products. National Renewable Energy Lab, Golden. https://doi.org/10.2172/1159351

Davis R, Markham J, Kinchin C, Grundl N, Tan ECD, Humbird D (2016) Process design and economics for the production of algal biomass algal biomass production in open pond systems and processing through dewatering for downstream conversion. National Renewable Energy Lab, Golden. https://doi.org/10.2172/1239893

Demirel $Y$ (2016) Energy production, conversion, storage, conservation, and coupling, 2nd edn. Springer, London. https://doi.org/10.1007/978-3319-29650-0

Demirel Y (2018a) Sugar versus lipid for sustainable biofuels. Int J Energy Res 42:881-884. https://doi.org/10.1002/er.3914

Demirel Y (2018b) Biofuels. In: Comprehensive energy systems. Elsevier, New York, pp 875-908. https://doi.org/10.1016/B978-0-12-809597-3.00125-5

Dillschneider R, Posten C (2013) Closed bioreactors as tools for microalgae production. In: Lee JW (ed) Advanced biofuels and bioproducts. Springer, New York, pp 629-649. https://doi.org/10.1007/978-1-4614-3348-4_26

Ehimen EA, Sun ZF, Carrington CG, Birch EJ, Eaton-Rye JJ (2011) Anaerobic digestion of microalgae residues resulting from the biodiesel production process. Appl Energy 88:3454-3463. https://doi.org/10.1016/j. apenergy.2010.10.020

Energy Department (2010) Annual energy outlook 2010: with projections to 2035. Government Printing Office, Washington 
Eroglu E, Smith SM, Raston CL (2015) Biomass and biofuels from microalgae, vol 2. Springer, Cham. https://doi.org/10.1007/978-3-319-16640-7

Ferrell J, Sarisky-Reed V (2010) National algal biofuels technology roadmap. US Dept. Energy 140. Public Law No.106-554

Ferroukhi R, Nagpal D, Lopez-Peña A, Hodges T, Mohtar RH, Daher B, Keulertz $M$ (2015) Renewable energy in the water, energy and food nexus. IRENA, Abu Dhabi

Fortier M-OP, Sturm BSM (2012) Geographic analysis of the feasibility of collocating algal biomass production with wastewater treatment plants. Environ Sci Technol 46:11426-11434. https://doi.org/10.1021/es302127f

Frank ED, Elgowainy A, Han J, Wang Z (2013) Life cycle comparison of hydrothermal liquefaction and lipid extraction pathways to renewable diesel from algae. Mitig Adapt Strateg Glob Chang 18(1):137-158

Geider R, La Roche J (2002) Redfield revisited: variability of C:N:P in marine microalgae and its biochemical basis. Eur J Phycol 37:1-17. https://doi. org/10.1017/S0967026201003456

Ghasemi Naghdi F, González González LM, Chan W, Schenk PM (2016) Progress on lipid extraction from wet algal biomass for biodiesel production. Microb Biotechnol 9:718-726. https://doi.org/10.1111/1751-7915.12360

Griffiths MJ, Harrison STL (2009) Lipid productivity as a key characteristic for choosing algal species for biodiesel production. J Appl Phycol 21:493-507. https://doi.org/10.1007/s10811-008-9392-7

Halim R, Danquah MK, Webley PA (2012) Extraction of oil from microalgae for biodiesel production: a review. Biotechnol Adv 30:709-732. https://doi. org/10.1016/j.biotechadv.2012.01.001

Halim R, Harun R, Webley PA, Danquah MK (2013) Bioprocess engineering aspects of biodiesel and bioethanol production from microalgae. In: Lee JW (ed) Advanced biofuels and bioproducts. Springer, New York, pp 601-628. https://doi.org/10.1007/978-1-4614-3348-4_25

Hall CAS, Lambert JG, Balogh SB (2014) EROI of different fuels and the implications for society. Energy Policy 64:141-152. https://doi.org/10.1016/j. enpol.2013.05.049

Han D, Li Y, Hu Q (2013) Astaxanthin in microalgae: pathways, functions and biotechnological implications. Algae 28:131-147

Harun R, Doyle M, Gopiraj R, Davidson M, Forde GM, Danquah MK (2013) Process economics and greenhouse gas audit for microalgal biodiesel production, in: advanced biofuels and bioproducts. Springer, New York, pp 709-744

Hejazi MA, Wijffels RH (2004) Milking of microalgae. Trends Biotechnol 22:189-194. https://doi.org/10.1016/j.tibtech.2004.02.009

Hena S, Fatimah S, Tabassum S (2015) Cultivation of algae consortium in a dairy farm wastewater for biodiesel production. Water Res Ind 10:1-14

Hoffmann JP (1998) Wastewater treatment with suspended and nonsuspended algae. J Phycol 34:757-763. https://doi.org/10.104 6/j.1529-8817.1998.340757.x

Hu Q, Sommerfeld M, Jarvis E, Ghirardi M, Posewitz M, Seibert M, Darzins A (2008) Microalgal triacylglycerols as feedstocks for biofuel production: perspectives and advances. Plant J. 54:621-639. https://doi. org/10.1111/j.1365-313X.2008.03492.x

Jorquera O, Kiperstok A, Sales EA, Embiruçu M, Ghirardi ML (2010) Comparative energy life-cycle analyses of microalgal biomass production in open ponds and photobioreactors. Bioresour Technol 101:1406-1413. https ://doi.org/10.1016/j.biortech.2009.09.038

Kanakraj S, Dixit S (2016) A comprehensive review on degummed biodiesel. Biofuels 7:537-548. https://doi.org/10.1080/17597269.2016.1168021

Kargbo DM (2010) Biodiesel production from municipal sewage sludges. Energy Fuels 24:2791-2794. https://doi.org/10.1021/ef1001106

Kazamia E, Aldridge DC, Smith AG (2012) Synthetic ecology — a way forward for sustainable algal biofuel production? J Biotechnol 162:163-169. https://doi.org/10.1016/j.jbiotec.2012.03.022

Kesaano M, Sims RC (2014) Algal biofilm based technology for wastewater treatment. Algal Res 5:231-240. https://doi.org/10.1016/j.algal .2014 .02 .003

Ketzer F, Skarka J, Rösch C (2018) Critical review of microalgae LCA studies for bioenergy production. Bioenergy Res. 11:95-105. https://doi. org/10.1007/s12155-017-9880-1

Kheshgi HS, Jain AK (2003) Projecting future climate change: implications of carbon cycle model intercomparisons. Global Biogeochem Cycles. https://doi.org/10.1029/2001GB001842

Khoo HH, Sharratt PN, Das P, Balasubramanian RK, Naraharisetti PK, Shaik S (2011) Life cycle energy and $\mathrm{CO}_{2}$ analysis of microalgae-to-biodiesel: preliminary results and comparisons. Bioresour Technol 102:5800-5807. https://doi.org/10.1016/j.biortech.2011.02.055

Klein-Marcuschamer D, Turner C, Allen M, Gray P, Dietzgen RG, Gresshoff PM, Hankamer B, Heimann K, Scott PT, Stephens E, Speight R, Nielsen LK (2013) Technoeconomic analysis of renewable aviation fuel from microalgae, Pongamia pinnata, and sugarcane. Biofuels Bioprod Biorefining 7:416-428. https://doi.org/10.1002/bbb.1404

Knothe G (2010) Biodiesel and renewable diesel: a comparison. Prog Energy Combust Sci 36:364-373. https://doi.org/10.1016/j.pecs.2009.11.004

Lardon L, Hélias A, Sialve B, Steyer J-P, Bernard O (2009) Life-cycle assessment of biodiesel production from microalgae. Environ Sci Technol 43:6475-6481. https://doi.org/10.1021/es900705j

Lau PS, Tam NFY, Wong YS (1995) Effect of algal density on nutrient removal from primary settled wastewater. Environ Pollut 89:59-66. https://doi. org/10.1016/0269-7491(94)00044-E

Lee JY, Yoo C, Jun SY, Ahn CY, Oh HM (2010) Comparison of several methods for effective lipid extraction from microalgae. Bioresour Technol 101:S75-S77. https://doi.org/10.1016/j.biortech.2009.03.058

Li H, Liu Z, Zhang Y, Li B, Lu H, Duan N, Liu M, Zhu Z, Si B (2014) Conversion efficiency and oil quality of low-lipid high-protein and high-lipid lowprotein microalgae via hydrothermal liquefaction. Bioresour Technol 154:322-329. https://doi.org/10.1016/j.biortech.2013.12.074

Liu J, Ma X (2009) The analysis on energy and environmental impacts of microalgae-based fuel methanol in China. Energy Policy 37:1479-1488. https://doi.org/10.1016/j.enpol.2008.12.010

López Barreiro D, Zamalloa C, Boon N, Vyverman W, Ronsse F, Brilman W, Prins W (2013) Influence of strain-specific parameters on hydrothermal liquefaction of microalgae. Bioresour Technol 146:463-471. https://doi. org/10.1016/j.biortech.2013.07.123

Lorenz RT, Cysewski GR (2000) Commercial potential for Haematococcus microalgae as a natural source of astaxanthin. Trends Biotechnol 18:160-167

Lyon SR, Ahmadzadeh H, Murry MA (2015) Biomass and biofuels from microalgae, vol 2. Springer, Berlin, pp 95-115. https://doi.org/10.1007/978-3319-16640-7_695

Markou G, Depraetere O, Vandamme D, Muylaert K (2015) Cultivation of Chlorella vulgaris and Arthrospira platensis with recovered phosphorus from wastewater by means of zeolite sorption. Int J Mol Sci 16:4250-4264. https://doi.org/10.3390/ijms16024250

Matzen M, Demirel Y (2016) Methanol and dimethyl ether from renewable hydrogen and carbon dioxide: alternative fuels production and life-cycle assessment. J Clean Prod 139:1068-1077. https://doi. org/10.1016/j.jclepro.2016.08.163

Matzen M, Alhaji M, Demirel Y (2015) Chemical storage of wind energy by renewable methanol production: feasibility analysis using a multicriteria decision matrix. Energy 93:343-353. https://doi.org/10.1016/j. energy.2015.09.043

Mchenry MP (2015) Biomass and biofuels from microalgae. Biofuel and biorefinery technologies. Springer, Cham. https://doi.org/10.1007/9783-319-16640-7

Mehta SK, Gaur JP (2005) Use of algae for removing heavy metal ions from wastewater: progress and prospects. Crit Rev Biotechnol 25:113-152. https://doi.org/10.1080/07388550500248571

Mercer P, Armenta RE (2011) Developments in oil extraction from microalgae. Eur J Lipid Sci Technol 113:539-547. https://doi.org/10.1002/ejlt.20100 0455

Metherel AH, Taha AY, Izadi H, Stark KD (2009) The application of ultrasound energy to increase lipid extraction throughput of solid matrix samples (flaxseed), Prostaglandins Leukot. Essent Fat Acids 81:417-423. https:// doi.org/10.1016/.jplefa.2009.07.003

Molina Grima E, Belarbi EH, Acién Fernández FG, Robles Medina A, Chisti Y (2003) Recovery of microalgal biomass and metabolites: process options and economics. Biotechnol Adv 20:491-515. https://doi. org/10.1016/S0734-9750(02)00050-2

Mooij PR, Stouten GR, van Loosdrecht MCM, Kleerebezem R (2015) Ecologybased selective environments as solution to contamination in microalgal cultivation. Curr Opin Biotechnol 33:46-51. https://doi. org/10.1016/j.copbio.2014.11.001

Mubarak M, Shaija A, Suchithra TV (2015) A review on the extraction of lipid from microalgae for biodiesel production. Algal Res 7:117-123. https:// doi.org/10.1016/j.algal.2014.10.008 
Muñoz R, Guieysse B (2006) Algal-bacterial processes for the treatment of hazardous contaminants: a review. Water Res 40:2799-2815. https://doi. org/10.1016/j.watres.2006.06.011

Mussgnug JH, Klassen V, Schlüter A, Kruse O (2010) Microalgae as substrates for fermentative biogas production in a combined biorefinery concept. J Biotechnol 150:51-56. https://doi.org/10.1016/j.jbiotec.2010.07.030

Muylaert K, Beuckels A, Depraetere O (2015) Biomass and Biofuels from Microalgae. Springer 2:75-94. https://doi.org/10.1007/978-3-319-16640-7

Nalley JO, Stockenreiter M, Litchman E (2014) Community ecology of algal biofuels: complementarity and trait-based approaches. Ind Biotechnol 10:191-201. https://doi.org/10.1089/ind.2013.0038

National Research Council (2012a) Renewable fuel standard: potential economic and environmental effects of US biofuel policy. National Academies Press, Washington, p 2012

National Research Council (2012b) Sustainable development of algal biofuels in the United States, vol 51. National Academies Press, Washington. https://doi.org/10.17226/13437

Neveux N, Yuen AKL, Jazrawi C, Magnusson M, Haynes BS, Masters AF, Montoya A, Paul NA, Maschmeyer T, de Nys R (2014) Biocrude yield and productivity from the hydrothermal liquefaction of marine and freshwater green macroalgae. Bioresour Technol 155:334-341. https:// doi.org/10.1016/j.biortech.2013.12.083

Nguyen N, Demirel Y (2011a) Using thermally coupled reactive distillation columns in biodiesel production. Pres 2010(36):4838-4847. https://doi. org/10.1016/j.ener-gy.2011.05.020

Nguyen NT, Demirel Y (2011 b) A novel biodiesel and glycerol carbonate production plant. Int J Chem React Eng. https://doi. org/10.2202/1542-6580.2856

Nguyen N, Demirel Y (2013) Economic analysis of biodiesel and glycerol carbonate production plant by glycerolysis. J Sustain Bioenergy Syst 03:209-216. https://doi.org/10.4236/jsbs.2013.33029

Nrel (1998) A look back at the US Department of Energy's aquatic species program: biodiesel from algae. Report 328:291. https://doi. org/10.2172/15003040

Olkiewicz M, Caporgno MP, Font J, Legrand J, Lepine O, Plechkova NV, Pruvost J, Seddon KR, Bengoa C (2015) A novel recovery process for lipids from microalgae for biodiesel production using a hydrated phosphonium ionic liquid. Green Chem 17:2813-2824. https://doi.org/10.1039/c4gc0 $2448 f$

Passell H, Dhaliwal H, Reno M, Wu B, Ben Amotz A, Ivry E, Gay M, Czartoski T, Laurin L, Ayer N (2013) Algae biodiesel life cycle assessment using current commercial data. J Environ Manage 129:103-111. https://doi. org/10.1016/j.jenvman.2013.06.055

Peccia J, Haznedaroglu B, Gutierrez J, Zimmerman JB (2013) Nitrogen supply is an important driver of sustainable microalgae biofuel production. Trends Biotechnol 31:134-138. https://doi.org/10.1016/j.tibte ch.2013.01.010

Pienkos PT, Darzins A (2009) The promise and challenges of microalgalderived biofuels. Biofuels Bioprod Biorefining 3:431-440. https://doi. org/10.1002/bbb.159

Pulz O, Gross W (2004) Valuable products from biotechnology of microalgae. Appl Microbiol Biotechnol 65:635-648. https://doi.org/10.1007/s0025 3-004-1647-x

Raeesossadati MJ, Ahmadzadeh H (2015) Biomass and biofuels from microalgae 2:117-136. https://doi.org/10.1007/978-3-319-16640-7

Ranjith Kumar R, Hanumantha Rao P, Arumugam M (2015) Lipid extraction methods from microalgae: a comprehensive review. Front Energy Res 2:1-9. https://doi.org/10.3389/fenrg.2014.00061

Rawat I, Ranjith Kumar R, Mutanda T, Bux F (2011) Dual role of microalgae: phycoremediation of domestic wastewater and biomass production for sustainable biofuels production. Appl Energy 88:3411-3424. https ://doi.org/10.1016/j.apenergy.2010.11.025

Razon LF, Tan RR (2011) Net energy analysis of the production of biodiesel and biogas from the microalgae: Haematococcus pluvialis and nannochloropsis. Appl Energy 88:3507-3514. https://doi.org/10.1016/j. apenergy.2010.12.052

Resurreccion EP, Colosi LM, White MA, Clarens AF (2012) Comparison of algae cultivation methods for bioenergy production using a combined life cycle assessment and life cycle costing approach. Biores Technol 126:298-306
Richardson JW, Johnson MD, Outlaw JL (2012) Economic comparison of open pond raceways to photo bio-reactors for profitable production of algae for transportation fuels in the Southwest. Algal Res 1:93-100. https://doi.org/10.1016/j.algal.2012.04.001

Roberts GW, Fortier MOP, Sturm BSM, Stagg-Williams SM (2013) Promising pathway for algal biofuels through wastewater cultivation and hydrothermal conversion. Energy Fuels 27:857-867. https://doi. org/10.1021/ef3020603

Rodolfi L, Zittelli GC, Bassi N, Padovani G, Biondi N, Bonini G, Tredici MR (2009) Microalgae for oil: strain selection, induction of lipid synthesis and outdoor mass cultivation in a low-cost photobioreactor. Biotechnol Bioeng 102:100-112. https://doi.org/10.1002/bit.22033

Rosenberg JN, Oyler GA, Wilkinson L, Betenbaugh MJ (2008) A green light for engineered algae: redirecting metabolism to fuel a biotechnology revolution. Curr Opin Biotechnol 19:430-436. https://doi. org/10.1016/j.copbio.2008.07.008

Sahena F, Zaidul ISM, Jinap S, Karim AA, Abbas KA, Norulaini NAN, Omar AKM (2009) Application of supercritical $\mathrm{CO}_{2}$ in lipid extraction-a review. J Food Eng 95:240-253. https://doi.org/10.1016/j.jfood eng.2009.06.026

Sander K, Murthy GS (2010) Life cycle analysis of algae biodiesel. Int J Life Cycle Assess 15:704-714. https://doi.org/10.1007/s11367-010-0194-1

Santana A, Jesus S, Larrayoz MA, Filho RM (2012) Supercritical carbon dioxide extraction of algal lipids for the biodiesel production. Procedia Eng 42:1755-1761. https://doi.org/10.1016/j.proeng.2012.07.569

Scott SA, Davey MP, Dennis JS, Horst I, Howe CJ, Lea-Smith DJ, Smith AG (2010) Biodiesel from algae: challenges and prospects. Curr Opin Biotechnol 21:277-286. https://doi.org/10.1016/j.copbio.2010.03.005

Sevigné Itoiz E, Fuentes-Grünewald C, Gasol CM, Garcés E, Alacid E, Rossi S, Rieradevall J (2012) Energy balance and environmental impact analysis of marine microalgal biomass production for biodiesel generation in a photobioreactor pilot plant. Biomass Bioenerg 39:324-335. https ://doi.org/10.1016/j.biombioe.2012.01.026

Shuping Z, Yulong W, Mingde Y, Kaleem I, Chun L, Tong J (2010) Production and characterization of bio-oil from hydrothermal liquefaction of microalgae Dunaliella tertiolecta cake. Energy 35:5406-5411. https:// doi.org/10.1016/j.energy.2010.07.013

Shurin JB, Abbott RL, Deal MS, Kwan GT, Litchman E, Mcbride RC, Mandal S, Smith VH (2013) Industrial-strength ecology: trade-offs and opportunities in algal biofuel production. Ecol Lett 16:1393-1404. https://doi. org/10.1111/ele.12176

Silva C, Soliman E, Cameron G, Fabiano LA, Seider WD, Dunlop EH, Coaldrake AK (2014) Commercial-scale biodiesel production from algae. Ind Eng Chem Res 53:5311-5324. https://doi.org/10.1021/ie403273b

Smith VH, Crews T (2014) Applying ecological principles of crop cultivation in large-scale algal biomass production. Algal Res 4:23-34. https:// doi.org/10.1016/j.algal.2013.11.005

Smith VH, Mcbride RC (2015) Key ecological challenges in sustainable algal biofuels production. J Plankton Res 37:671-682. https://doi. org/10.1093/plankt/fbv053

Sommerfeld M, Chen W, Hu Q, Giorgi D, Navapanich T, Ingram M et al (2008) Application of electroporation for lipid extraction from microalgae. Algae Biomass Summit, Seattle

Spoalore P, Joannis-Cassan C, Duran E, Isambert A (2006) Commercial application of microalgae. J Biosci Bioeng 101:87-96

Stephens E, Ross IL, Mussgnug JH, Wagner LD, Borowitzka MA, Posten C, Kruse O, Hankamer B (2010) Future prospects of microalgal biofuel production systems. Trends Plant Sci 15:554-564. https://doi.org/10.1016/j. tplants.2010.06.003

Stephenson AL, Kazamia E, Dennis JS, Howe CJ, Scott SA, Smith AG (2010) Lifecycle assessment of potential algal biodiesel production in the united kingdom: a comparison of raceways and air-lift tubular bioreactors. Energy Fuels 24:4062-4077. https://doi.org/10.1021/ef1003123

Sturm BSM, Lamer SL (2011) An energy evaluation of coupling nutrient removal from wastewater with algal biomass production. Appl Energy 88:3499-3506. https://doi.org/10.1016/j.apenergy.2010.12.056

Suali E, Sarbatly R (2012) Conversion of microalgae to biofuel. Renew Sustain Energy Rev 16:4316-4342. https://doi.org/10.1016/j.rser.2012.03.047

Suarsini E, Subandi (2011) Utilization ultrasonic to increase the efficiency of oil extraction for microalgae indigenous isolates from pond gresik, east 
java. In: 2011 IEEE conference on clean energy and technology (CET). IEEE, New York. pp. 275-279. https://doi.org/10.1109/CET.2011.6041496 Togarcheti SC, Mediboyina MK, Chauhan VS, Mukherji S, Ravi S, Mudliar SN (2017) Life cycle assessment of microalgae based biodiesel production to evaluate the impact of biomass productivity and energy source. Resour Conserv Recycl 122:286-294. https://doi.org/10.1016/j.resco nrec.2017.01.008

Toor S, Reddy, H, Deng S, Hoffmann J, Holm-Nielsen JB, Rosendahl L (2013) Hydrothermal liquefaction of microalgae's for bio oil production. www. forskningsdatabasen.dk/en/catalog/2389364184

Travieso L, Benitez F, Dupeiron R (1992) Sewage treatment using immobilied microalgae. Bioresour Technol 40:183-187. https://doi. org/10.1016/0960-8524(92)90207-E

Trivedi J, Aila M, Bangwal DP, Kaul S, Garg MO (2015) Algae based biorefinery-how to make sense? Renew Sustain Energy Rev 47:295-307. https ://doi.org/10.1016/j.rser.2015.03.052

Umdu ES, Tuncer M, Seker E (2009) Transesterification of Nannochloropsis oculata microalga's lipid to biodiesel on $\mathrm{Al}_{2} \mathrm{O}_{3}$ supported $\mathrm{CaO}$ and $\mathrm{MgO}$ catalysts. Bioresour Technol 100:2828-2831. https://doi.org/10.1016/j. biortech.2008.12.027

Valdez PJ, Dickinson JG, Savage PE (2011) Characterization of product fractions from hydrothermal liquefaction of Nannochloropsis sp. and the influence of solvents. Energy Fuels 25:3235-3243. https://doi.org/10.1021/ ef2004046

Vandamme D, Foubert I, Muylaert K (2013) Flocculation as a low-cost method for harvesting microalgae for bulk biomass production. Trends Biotechnol 31:233-239. https://doi.org/10.1016/j.tibtech.2012.12.005
Vardon DR, Sharma BK, Scott J, Yu G, Wang Z, Schideman L, Zhang Y, Strathmann TJ (2011) Chemical properties of biocrude oil from the hydrothermal liquefaction of Spirulina algae, swine manure, and digested anaerobic sludge. Bioresour Technol 102:8295-8303. https:// doi.org/10.1016/j.biortech.2011.06.041

Wang J, Chen C (2009) Biosorbents for heavy metals removal and their future. Biotechnol Adv 27:195-226. https://doi.org/10.1016/j.biotechadv .2008.11.002

Wang H, Zhang W, Chen L, Wang J, Liu T (2013) The contamination and control of biological pollutants in mass cultivation of microalgae. Bioresour Technol 128:745-750. https://doi.org/10.1016/j.biortech.2012.10.158

Wijffels RH, Barbosa MJ, Eppink MHM (2010) Microalgae for the production of bulk chemicals and biofuels. Biofuels Bioprod Biorefining 4:287-295. https://doi.org/10.1002/bbb.215

Withers JW, Quesada-Pineda HJ, Smith RL (2017) Bioeconomy survey results regarding barriers to the United States advanced biofuel industry. BioResources 12(2):2846-2863

Woertz I, Feffer A, Lundquist T, Nelson Y (2009) Algae grown on dairy and municipal wastewater for simultaneous nutrient removal and lipid production for biofuel feedstock. J Environ Eng 135:1115-1122. https:// doi.org/10.1061/(ASCE)EE.1943-7870.0000129

Yanfen L, Zehao H, Xiaoqian M (2012) Energy analysis and environmental impacts of microalgal biodiesel in China. Energy Policy 45:142-151

Yoo G, Park WK, Kim CW, Choi YE, Yang JW (2012) Direct lipid extraction from wet Chlamydomonas reinhardtii biomass using osmotic shock. Bioresour Technol 123:717-722. https://doi.org/10.1016/j.biort ech.2012.07.102

\section{Submit your manuscript to a SpringerOpen ${ }^{\circ}$ journal and benefit from:}

- Convenient online submission

- Rigorous peer review

- Open access: articles freely available online

- High visibility within the field

- Retaining the copyright to your article

Submit your next manuscript at $\boldsymbol{\nabla}$ springeropen.com 